\title{
Analyses of robotic traverses and sample sites in the Schrödinger basin for the HERACLES human-assisted sample return mission concept
}

DOI:

10.1016/j.asr.2016.05.041

\section{Document Version}

Accepted author manuscript

Link to publication record in Manchester Research Explorer

Citation for published version (APA):

Steenstra, E. S., Martin, D. JP., McDonald, F. E., Paisarnsombat, S., Venturino, C., O'Hara, S., Calzada-Diaz, A., Bottoms, S., Leader, M. K., \& Klaus, K. K. (2016). Analyses of robotic traverses and sample sites in the Schrödinger basin for the HERACLES human-assisted sample return mission concept. Advances in Space Research. https://doi.org/10.1016/j.asr.2016.05.041

\section{Published in:}

Advances in Space Research

\section{Citing this paper}

Please note that where the full-text provided on Manchester Research Explorer is the Author Accepted Manuscript or Proof version this may differ from the final Published version. If citing, it is advised that you check and use the publisher's definitive version.

\section{General rights}

Copyright and moral rights for the publications made accessible in the Research Explorer are retained by the authors and/or other copyright owners and it is a condition of accessing publications that users recognise and abide by the legal requirements associated with these rights.

\section{Takedown policy}

If you believe that this document breaches copyright please refer to the University of Manchester's Takedown Procedures [http://man.ac.uk/04Y6Bo] or contact uml.scholarlycommunications@manchester.ac.uk providing relevant details, so we can investigate your claim.

\section{OPEN ACCESS}


1 Analyses of Robotic Traverses and Sample Sites in the 2 Schrödinger basin for the HERACLES Human-Assisted 3 Sample Return Mission Concept

Edgar S. Steenstra ${ }^{a}$, Dayl J. P. Martin ${ }^{b}$, Francesca E. McDonald ${ }^{b}$, Sarinya Paisarnsombat ${ }^{c}$ Christian Venturino ${ }^{d}$, Sean O'Hara $^{\mathrm{e}}$, Abigail Calzada-Diaz ${ }^{\mathrm{f}}$, Shelby Bottoms ${ }^{\mathrm{g}}$, Mark K. Leader ${ }^{\mathrm{g}}$, Kurt K. Klaus ${ }^{g}$, Wim van Westrenen ${ }^{\text {a }}$, Debra H. Needham ${ }^{\text {h }}$, David A. Kringi

${ }^{\mathrm{a}}$ Faculty of Earth and Life Sciences, VU University, Amsterdam, The Netherlands

${ }^{b}$ School of Earth, Atmospheric and Environmental Sciences, University of Manchester, UK

'Department of Earth Sciences, University of New Brunswick, Canada

${ }^{d}$ Department of Geology, University at Buffalo, Buffalo, USA

${ }^{e}$ Department of Earth and Environmental Science, University of Illinois at Chicago, Chicago, USA

${ }^{f}$ Department of Earth and Planetary Science, Birkbeck University of London, UK

${ }^{g}$ The Boeing Company, Houston, USA

${ }^{h}$ Goddard Space Flight Center, Oak Ridge Associated Universities, USA

'Center for Lunar Science and Exploration, Lunar and Planetary Institute, USA

*Corresponding author: email address: e.s.steenstra@vu.nl

Telephone: +316-29573045

\section{Abstract}

Near-future exploration of the Moon will likely be conducted with human-operated robotic assets. Previous studies have identified the Schrödinger basin, situated on the far side of the Moon, as a prime target for lunar science and exploration where a significant number of the scientific concepts reviewed by the National Research Council (NRC, 2007) can be addressed. In this study, two robotic mission traverses within Schrödinger basin are proposed based on a 3 year mission plan in support of the HERACLES human-assisted sample return mission concept. A comprehensive set of modern remote sensing data (LROC imagery, LOLA topography, $\mathrm{M}^{3}$ and Clementine spectral data) has been integrated to provide high-resolution coverage of the traverses and to facilitate identification of 
specific sample localities. We also present a preliminary Concept of Operations (ConOps) study based on

a set of notional rover capabilities and instrumental payload. An extended robotic mission to Schrödinger basin will allow for significant sample return opportunities from multiple distinct geologic terrains and will address multiple high-priority NRC (2007) scientific objectives. Both traverses will offer the first opportunity to (i) sample pyroclastic material from the lunar farside, (ii) sample Schrödinger impact melt and test the lunar cataclysm hypothesis, (iii) sample deep crustal lithologies in an uplifted peak ring and test the lunar magma ocean hypothesis and (iv) explore the top of an impact melt sheet, enhancing our ability to interpret Apollo samples. The shorter traverse will provide the first opportunity to sample farside mare deposits, whereas the longer traverse has significant potential to collect SPA impact melt, which can be used to constrain the basin-forming epoch.

Keywords: Schrödinger, Moon, Exploration, Lunar, Sample Return Mission

\section{Introduction}

The international community agrees (e.g., NRC, 2007; Crawford et al., 2012) that exploration of the Moon can address fundamentally important scientific questions, while providing a credible path for human exploration into the Solar System. The International Space Exploration Coordination Group (ISECG), an interagency organization developing an integrated Global Exploration Roadmap (GER), is currently exploring a human-assisted robotic sample return mission concept (HERACLES; HumanEnhanced Robotic Architecture and Capability for Lunar Exploration and Science). This mission concept involves a series of landings that would expand access to the lunar surface. The first landing would deploy the rover. Two additional landings of a reusable ascent vehicle at other sites along the traverse would deploy a suite of experimental packages. The rover collects samples and performs in-situ analyses during each section of the traverse for a number of months, and rendezvous with the ascent vehicle to transfer the collected samples. A crew in the Orion capsule or an exploration Deep Space Habitat (eDSH) could tele-operate the rover while orbiting at the Earth-Moon L2 Lagrange point above the farside of the Moon (Burns et al., 2013; Pratt et al., 2014). The samples for each section would then be transferred

57 from the ascent vehicle to the eDSH, which would transfer the samples to the Orion crew vehicle for return to Earth.

One of the most comprehensive studies of lunar science objectives conducted by the US National investigations (NRC, 2007). A large number of studies were then conducted to determine the locations 
on the lunar surface where those investigations could be addressed (Kring and Durda, 2012). This work showed that the Schrödinger basin, situated within the South Pole-Aitken (SPA) basin, is the best location on the Moon for addressing the highest priority and largest number of objectives.

For example, a robotic sample return mission to Schrödinger basin would test the cataclysm hypothesis (NRC Goal 1), would provide insights into the the petrologic structure of the lunar interior (NRC Goals 2 and 3), would assess the thermal and compositional evolution of the Moon (NRC Goals 3 and 5), would provide insights into basin forming processes (NRC Goal 6) and would investigate regolith processes and surface weathering (NRC Goal 7). A recent study of Kumar et al. (2015) suggests that the Schrödinger basin is also an interesting locality for studying local seismic events and could be tied into a tetrahedral seismic array for global lunar coverage (Tian et al., 2013). In addition, several targets within the peak ring structure are likely to receive no or little illumination year-round and are therefore believed to be targets suitable for in-situ resource utilization (ISRU) (Kring et al., 2014; NRC Goal 4). The pyroclastic vent is believed to be a prominent source of volatiles and, therefore, also has a significant ISRU potential (Kring, 2014). Previous studies have referenced these benefits to justify a range of sites and traverses that are located within the Schrödinger basin. However, these mission designs involved either human exploration on the lunar surface (Bunte et al., 2011; O'Sullivan et al., 2011) or a robotic exploration mission that does not exceed more than one lunar day (Potts et al., 2015).

In this study, two possible traverses for long-term ( 3 year) robotic exploration in the Schrödinger basin are investigated by integrating a wide range of remote sensing datasets that include topography, compositional spectra, and high-resolution imagery (Martin et al., 2016; McDonald et al., 2016). The proposed traverses are based on previously identified key targets within Schrödinger basin (O'Sullivan et al., 2011; Potts et al., 2015; Hurwitz and Kring, 2015) and are designed to address the key science and exploration objectives that are prevalent throughout the international lunar science community (NRC, 2007; Crawford et al., 2012).

\section{The Schrödinger basin}

The Schrödinger impact basin (Fig. 1, 2) is located on the lunar farside $\left(-75^{\circ}, 132.5^{\circ}\right)$ and is the secondyoungest basin formed during the basin-forming epoch. It is situated within the South Pole-Aitken (SPA) basin, the oldest and largest impact basin on the Moon. Schrödinger measures $320 \mathrm{~km}$ in diameter and its basin floor has a minimum elevation of $\sim 4.5 \mathrm{~km}$ below the crater rim. Despite subsequent modification by both volcanism and secondary cratering from nearby large impacts, Schrödinger is remarkably well preserved. It features a distinctive inner peak ring measuring $\sim 150 \mathrm{~km}$ in 
diameter, extending up to $2.5 \mathrm{~km}$ above the basin floor, and possessing a discontinuous southern region due, probably, to overlapping with the Amundsen-Ganswindt basin (Shoemaker et al., 1994). The peak ring preserves pre-Schrödinger materials uplifted from a depth of $\sim 20-30 \mathrm{~km}$, implying the presence of mid- to deep-crustal lithologies (Kring et al., 2013). The modification of Schrödinger basin is likely to have exposed SPA-derived material within its southern wall which would be of great significance as sampling this material would address the two top ranking NRC (2007) science objectives (Hurwitz and Kring, 2015).

101

Fig. 1, Fig. 2

103

Traverse routes within the Schrödinger basin were constructed in ArcGIS@ 10.1 using Lunar 106 Reconnaissance Orbiter Camera (LROC) NAC (Narrow Angle Camera; $0.5 \mathrm{~m} /$ pix resolution) and WAC (Wide Angle Camera; $100 \mathrm{~m} / \mathrm{pix}$ ) images, integrated with a Digital Elevation Map (DEM from Lunar Orbiter Laser Altimeter). Spectral reflectance data, collected by $\mathrm{M}^{3}$ and documented in the geologic map of Kramer et al. (2013), was also used to supplement these datasets to select sample sites along traverses. The WAC images were combined with Lunar Orbiter Laser Altimeter (LOLA) data to create a DEM with a spatial resolution of $100 \mathrm{~m} /$ pix. A set of 3D images were created by combining NAC imagery and the DEM in ArcScene $C$. Spectral data from the Clementine mission were used to interpret the FeO variability across the basin (Lucey et al., 2000; Kramer et al., 2013; Hurwitz and Kring, 2015).

\section{Rover capabilities and operations}

\subsection{Rover capabilities and notional instrument payload}

The interpretation of returned samples benefits significantly from knowledge of the geological context of the sampled area. A first order criterion for instrument selection is, therefore, their demonstrated capability to provide regional and lateral geological context of the sample site. A notional payload that might be used to perform in-situ analyses along the proposed traverse include a Ground Penetrating Radar (GPR) (ExoMars WISDOM, Shearer et al., 2010), a HD imager (Mars Science Laboratory MastCam, Shearer et al., 2010), a Gamma Ray Spectrometer or GRS (JH APL, Wieczorek et al., 2015) and a Microscope Imager (MI) (Mars Exploration Rover, Arvidson and May, 2010). Other instruments may include an arm-mounted Alpha Particle X-Ray Spectrometer or APXS (Mars Exploration Rover, Arvidson and May, 2010) and a Neutron Spectrometer or NS (Lunar Prospector / 
Hydra, Shearer et al., 2010).

A continuously operating GPR would provide a measure of the lateral and vertical distribution of subsurface lithologies along the traverses and a HD camera would be used to image different areas along the traverse to provide regional geological context. A MI can be used to investigate the physical and chemical properties either of the target material at the sub-millimeter scales, or adjacent material to provide additional geological context. Subsurface $(<10 \mathrm{~cm})$ elemental abundances for a wide range of elements can be obtained using a GRS in conjunction with an arm-mounted APXS. The APXS is particularly important as it can provide rapid compositional analysis ( $\sim 30-60$ minutes) of the target material with a reasonable degree of accuracy (Rieder et al., 2003). Operation of a NS would assess volatile composition and distribution and, therefore, provide a measure of ISRU potential within the Schrödinger basin. To sample regolith or other poorly consolidated material, a percussive scoop or shovel tool would be required (Craft et al., 2009; Zacny et al., 2009). Collection of uniformly sized lithic fragments would require a rake tool, which may have to be developed.

Sampling of boulders and outcrops along the traverse also requires the robotic asset to remove these samples without completely destroying textural data. Techniques that could be implemented include coring devices (Johnson et al., 2009; Myrick et al., 2012; Paulsen et al., 2012; Zacny et al., 2012, 2013) or rock chipping devices (Barnouin-Jha et al., 2004). Prior to identification and analysis procedures, a Rock Abrasion Tool (RAT) could be used to expose the interior of lunar rock samples (Myrick et al., 2004).

Technical aspects of the assumed notional instrument payload, including weight and average power consumption, are summarized in Table 1 . The proposed traverses in this study could be explored with any instrument payload and the notional payload included here is simply used to demonstrate the science potential of the traverses and to create a rational concept of operations from which to determine analytical timelines and data bandwidths. The rover speed is assumed to be $0.36 \mathrm{~km} / \mathrm{hr}$ based on the expected speed of the Resource Prospector rover (Loftin et al., 2013), a conservative estimate given the speed of $0.8-2 \mathrm{~km} / \mathrm{hr}$ of the Soviet Lunokhod rover (Seeni et al., 2010). We consider a maximum traversable slope of $16^{\circ}$, because wheel enabled systems show considerable difficulties at higher slopes due to a sudden drop in slip ratio (Seeni et al., 2010; Potts et al., 2015). 
The operations that the rover will perform at stations as well as start-up and packing down processes required for traversing along the lunar surface are defined as the ConOps. The HERACLES human-assisted sample return mission concept is based on a 3 year mission duration and the rover must therefore be able to survive a large number of lunar nights ( 14 Earth days) during which it will hibernate. This strategy is similar to the Lunokhod 1 rover that survived for 7 to 11 lunar nights and Lunokhod 2 that survived $\sim 5$ lunar nights (Petrov, 1972; NASA Space Science Data Center, 1970, 1973). The time estimated to deploy the rover is 20 hours (Potts et al., 2015). Before and after each hibernation period, $\sim 24$ hours is allocated for powering down and up of the rover (Potts et al., 2015). teams in Orion and on Earth dually conduct rover operations. Each of the three sample transfer procedures from the rover to the ascent vehicle are estimated to take $\sim 10$ hours (Potts et al., 2015). Along the traverse, sampling and in-situ analysis stations were identified. At each sampling station, the rover will first stop to collect a GigaPan panorama using the surface imaging camera ( 8 hrs). The rover will then select a target and will move to its location, where it will position itself ( $\sim 0.5$ hrs). Once in place, the rover is expected to conduct a number of analyses, including APXS ( $\sim 3.5$ hrs/analysis), GRS ( 1.5 hrs/analysis) and MI ( 1.5 hrs/analysis). The GPR is expected to operate constantly while traversing, but NS analyses would only be used at specific targets ( 6.5 hrs/analysis). Images taken before and after sampling will provide context for the returned samples ( $\sim \mathrm{hr})$. An additional $\sim 4$ hours is required for sample collection ( $\sim 3 \mathrm{hrs}$ ) and storage ( $\sim 1 \mathrm{hr})$. Assuming one APXS, MI and GRS analysis, 19.5 hours would be spent at each sampling station (Table 2). For in-situ analysis stations, the average time spent at each station is estimated to $\sim 15.5$ hours. This does not take into account any additional time that may be required to repeat analyses, load commands, or to address unforeseeable issues (e.g., obstacle avoidance or stuck wheels). There is, however, plenty of margin in the ConOps schedule to mitigate these types of issues as described below.

\section{Table 2}

\subsection{Soil mechanics and rover trafficability}

Lunar soil properties may affect the maneuverability and power usage of a robotic rover and is an important constraint on possible traverse designs. Photographic observations of footprints and Lunar Roving Vehicle (LRV tracks) from the Apollo era allow for the calculation of surficial porosity, cohesion, 
and friction angles of lunar regolith (Mitchell et al., 1972). These results suggest that the rims of primary and secondary craters covered with significant amounts of ejecta should be circumvented due to their low trafficability. For example, the Lunokhod 2 rover experienced significant wheel sinkage $(\sim 20 \mathrm{~cm})$ when it traversed the soft soils within the rim of a Mare Serenitatis crater (Carrier et al., 1991). The wall slump material within Schrödinger basin may be analogous to the soft soils encountered on Apollo 15, during which the LRV rover wheels sank $\sim 13 \mathrm{~cm}$ into the lunar regolith (Carrier et al., 1991). However, the weight of the rover is likely to be significantly lower than the LRV and its much lower speed would reduce wheel spin, which would reduce the risk of significant wheel sinkage. A particular area of interest is the pyroclastic unit within Schrödinger, because the physical properties of lunar pyroclastic soils are poorly constrained. Apollo 17 regolith core samples from the Shorty crater rim suggested that the orange glass deposit was unusually compact, exhibiting high cohesion (Mitchell et al., 1973). The bearing capacity of a lunar soil is defined as its capability to support applied loads and is therefore a proxy for possible trafficability of a lunar rover. Using the surficial properties obtained for the upper part of the latter drill core combined with observed boulder tracks within the pyroclastic deposits close and within the vent (the Appendix), the bearing capacity of the pyroclastic material can be calculated using Terzaghi's bearing capacity equation for circular footings (Terzaghi, 1948) (Eq. 1):

$$
Q=1.3 N_{c} C+\rho g N_{q} D_{f}+0.6 \rho g N_{v} R_{f}
$$

where $N_{c}, N_{q}$, and $N_{\psi}$ are dimensionless numbers for soil shear conditions based on the internal friction angle. The boulder and associated track dimensions were used for the depth of footing $\left(D_{f}\right)$ and radius of footing $\left(R_{f}\right)$ values (Fig. 2). Cohesion (C) value is taken to be $10^{3}$ dynes $/ \mathrm{cm}^{2}$ (Moore, 1970; Hovland and Mitchell, 1969; Mitchell et al., 1973), gravity (g) as $163 \mathrm{~cm} / \mathrm{s}^{2}$ and the boulders are assumed to be spherical. Assuming an internal friction angle of $30^{\circ}$ and estimated pyroclastic soil density of $2.0 \mathrm{~g} / \mathrm{cm}^{3}$ (Moore, 1970; Hovland and Mitchell, 1969; Mitchell et al., 1973), we calculate a bearing capacity (Q) of $3.46 \times 10^{6}$ dynes $/ \mathrm{cm}^{2}$, comparable to the $9.28 \times 10^{5}$ dynes $/ \mathrm{cm}^{2}$ calculated by Moore (1970) for general lunar surface capacities (the Appendix). The friction angle of lunar pyroclastic deposits is not known. However, an increase of the friction angle to $35^{\circ}$, the suggested value for the upper $15 \mathrm{~cm}$ of regolith (Houston et al., 1972; Hovland and Mitchell, 1969; Mitchell et al., 1972, 1973), results in an increase of the bearing capacity to $6.41 \times 10^{6} \mathrm{dynes} / \mathrm{cm}^{2}$. The higher value associated with Schrödinger's pyroclastic unit demonstrates that it has a higher cohesion and capacity for added mass, meaning the 
222 trafficability for a robotic rover is likely sufficient (Venturino et al., 2016). This is important, as 15\%

223 and $\sim 30 \%$ of the proposed short and long traverses are located within the pyroclastic deposits.

224 However, there is some uncertainty in these calculations. For example, the reported internal friction

225 angles derived from boulder tracks range considerably between previous studies $\left(10-50^{\circ}\right.$; Moore, 1970;

226 Mitchell et al., 1973). It is also not clear to what extent the Apollo 17 orange glass soil density is

227 representative of the pyroclastic material within Schrödinger. Our calculations also do not take the

228 effect of the local slope on Terzaghi's bearing capacity equation for circular footings into account. If HERACLES is pursued, then this issue will need to be examined further.

230

231

232

233

234

235

236

237

238

239

240

\subsection{Sample mass considerations}

For the traverses proposed in this study, we assume an arbitrary sample mass of $10 \mathrm{~kg}$ per landing. However, the sample mass that can be returned will depend on the payload capability of the ascent vehicle. Assessment of the payload capability of a possible ascent vehicle suggests it is likely that $>10$ $\mathrm{kg}$ of sample mass can be accommodated (the Appendix). Another constraint on returned sample mass is the storage capability of the considered sample containers that are required for sample transfer between the ascent vehicle and the eDSH.

Calculations assuming a prototype spherical sample container (Pratt et al., 2014) suggests total sample masses can exceed $30 \mathrm{~kg}$ (the Appendix). The assumed $30 \mathrm{~kg}$ of total sample mass is, therefore, a baseline. A greater mass of representative returned samples would significantly increase the productivity of a robotic exploration mission in Schrödinger basin. These additional samples could be collected from a wide range of identified in-situ stations along both traverses. The size of sample collected at each station in the concept study is dependent on the type of lithology involved and is based on recommendations from the Curation and Analysis Planning Team for Extraterrestrial Materials (CAPTEM) (Shearer et al., 2007).

\section{Sampling key units within Schrödinger basin}

A significant number of key lithological units are present within the Schrödinger basin and sampling these units will address a wide range of scientific goals defined by the NRC (2007). These units include SPA-derived material and Schrödinger impact melt, crustal lithologies, secondary impactor material, and volcanic deposits (pyroclastic and mare) (Fig. 1, 2). Hurwitz and Kring (2015) showed that the southern basin wall of Schrödinger basin is a promising target for sampling SPA-derived material. In conjunction with samples of Schrödinger impact melt sheet, samples of SPA-derived material can be 
used to anchor the early Earth-Moon impact flux and basin forming epoch, addressing the top two science objectives (NRC, 2007). Along the peak ring area, a significant section of the lunar crust is exposed and includes anorthositic, noritic, and troctolitic lithologies (Fig. 1, 2). Sampling these lithologies would test models of planetary differentiation and crustal evolution (NRC Goals 2 and 3), provide ground-truth standards for remote sensing applications, and yield important insights into the 259 dynamical processes that occur during peak-ring basin forming events (NRC Goal 6). A large number of secondary craters thought to be related to the formation of Antoniadi crater and Orientale basin (Fig. 1, 2) have also been identified within the Schrödinger basin. By targeting such secondary craters, exotic material from different regions of the Moon could be sampled and analyzed (NRC Goal 1). Samples of the mare and pyroclastic volcanic deposits within the Schrödinger basin (Fig 1, 2) provide insight into their mantle source depths, the delivery mechanism to the surface (NRC Goals 2 and 3), and lunar thermal evolution (NRC Goal 5). The pyroclastic deposits may also be volatile-rich and sampling this material would evaluate its ISRU potential. Regolith samples and in-situ analyses will provide insights into regolith processes and surface weathering on the lunar surface (NRC Goal 7).

271 traverse is $\sim 207 \mathrm{~km}$ long and is designed to explore the basin interior. The second, longer traverse is $272 \sim 291 \mathrm{~km}$ long and is designed to explore the region between the basin interior and basin wall.

\section{Traverses}

Two traverses were designed within an ESA-specified total traverse distance of 100 to $300 \mathrm{~km}$. The first

\subsection{The short traverse}

The short traverse is situated within the inner peak ring area of the Schrödinger basin. Sampling along this traverse would access 6 of the geologic units defined by Kramer et al. (2013) and has the potential to address a significant number of the NRC (2007) science priorities (Table 2, Fig. 4, 5). The traverse is $\sim 207 \mathrm{~km}$ long and accommodates 50 stations with 18 sampling stations (the Appendix). The other 32 stations are identified as in-situ analysis stations, that are expected to significantly contribute to the geological context and, therefore, understanding of the returned samples. The traverse has been divided into three sections with three landing sites. The first section is based on Potts et al. (2015), but with a proposed $3 \mathrm{~km}$ shift to the north-west for the first landing site. This shift is required to prevent any contamination of the ascent vehicle activities on the first sample station (Immer et al., 2011). Stations S1-S9 will be visited in the first section and stations S10-S33 and S34-S50 will be investigated in the second and third leg of the traverse, respectively (the Appendix). 
Sampling stations S1, S14 and S24 are located within the pyroclastic deposits unit $(E p)$ that is associated with a pyroclastic vent (Wilhelms et al., 1979; Shoemaker et al., 1994; Gaddis et al., 2003; Kramer et al., 2013). The deposits are morphologically distinct from the surrounding terrain and their $\mathrm{M}^{3}$ spectral heterogeneities suggest the deposits are more FeO-rich than the surrounding basin floor (Kramer et al., 2013). This type of volcanic material was emplaced by a volatile-driven fire fountain eruption (Rutherford and Papale, 2009; Wetzel et al., 2015; Fig. 6). This is based on the analyses of presumably similar lunar pyroclastic deposits (e.g., Apollo 17 orange glass) which show a surface coating that is enriched in highly volatile elements relative to the bulk silicate Moon (Meyer et al., 1975). This is thought to be the result of deposition of volatile-rich vapors onto the glass beads during cooling of the volcanic gas clouds that envelop the beads (Hauri et al., 2015; Fig. 6). Previous studies have suggested the pyroclastic volcanism within Schrödinger basin occurred $<2$ Ga ago, which is relatively recent (Shoemaker et al., 1994) compared with the inferred age range of $\sim 4.0-1.2 \mathrm{Ga}$ of mare magmatism on the Moon (Hiesinger et al., 2011). Stations S1, S14 and S14 will provide the first opportunity to sample pyroclastic material in geological context from the lunar farside. Absolute dating of these samples will yield an absolute chronology of relatively young lunar processes and, therefore, will additionally constrain the lunar thermal evolution (NRC Goal 5). Samples of this material would also provide insights into the compositional evolution of the lunar interior (NRC Goals 2, 3, and 5) by determination of their source depth, formation mechanism, and ISRU potential (Kring, 2014; Kring et al., 2014). The results from in-situ analyses at stations S9-S13 and S15-S26 will provide insights into the vertical and lateral variability of the pyroclastic deposits, and can be used to further constrain its compositional variability and distribution (NRC Goal 2, 3 and 5).

S3 and S5 will sample lithologically distinct boulders derived from the peak ring (Fig. 5a, b). Spectral observations from the Kaguya spacecraft and the $\mathrm{M}^{3}$ instrument indicate the presence of anorthositic, noritic, and troctolitic lithologies at the peak ring (Kramer et al., 2013) (Fig. 1). This suggests that the peak ring material is composed of pre-Nectarian deep crust, and possibly upper mantle material, uplifted during the basin forming event (Kramer et al., 2013; Fig. 2). The anorthositic unit is interpreted to be crystalline material that has not been significantly shocked or melted, representative of pre-impact crustal material. This is derived from (1) the unmistakable spectral signature of pure anorthosite and (2) 
the estimated exhumation depth of the peak ring that exceeds the thickness of cumulative ejecta from all observable ancient basins in proximity to Schrödinger basin (Kramer et al., 2013). The troctolitic unit is likely to reflect lower crustal material or potentially entrained upper mantle material and may provide information of the pre-uplift depth, estimated to be 20-30 km (Kring et al., 2013). The eastern part of

322 the peak ring is well covered by $\mathrm{M}^{3}$ spectral reflectance data and is in close proximity to the pyroclastic 323 vent, providing an opportunity for maximizing the science and exploration potential in a relatively small area (Bunte et al., 2011; O'Sullivan et al., 2011; Potts et al., 2015). The identification of boulders and associated trails allows for sampling of peak material at slopes accessible to conventional rover designs (Potts et al., 2015) and will yield the first in-context samples of pristine middle and lower lunar crustal 327 lithologies.

This will test models of planetary differentiation and crustal evolution, therefore addressing the majority of the science priorities within NRC (2007) Goals 2 and 3. It will also yield insights into the dynamical processes that occur during peak ring basin forming events (NRC Goal 6) and provide groundtruth standards to test and refine interpretations based on remote sensing spectral data. In-situ analysis station S4 on pre-Nectarian peak ring material will provide additional insights into the vertical and lateral diversity of primitive, lunar crust. Because the competing models for peak ring formation (cf.

http://www.hou.usra.edu/meetings/lpsc2016/pdf/1659.pdf) assume different strengths for the material in peak rings, it will be important to produce high-resolution images of any peak-ring outcrops and boulders from those outcrops along the traverse.

Station S6 will involve the collection of a rake sample and is located close to the fracture north of the peak ring, where detailed imaging of the cliff wall will provide a regional geological cross section (Fig. 5b, c). In-situ analysis at station S7 and sampling at station S8 will study impact melt breccias from the inter-peak ring floor material (lipr) unit, which is thought to contain peak ring material and Schrödinger impact melt (Shoemaker et al., 1994; Kramer et al., 2013). This would be the first opportunity to explore and sample the top of an impact melt sheet on the Moon. Compositional spectra $\left(\mathrm{M}^{3}\right)$ suggest the dominant composition of the upper portion of the melt sheet is noritic (Kramer et al., 2013). This may 345 imply that the Schrödinger melt sheet differentiated during cooling, which is a topic of ongoing debate 346 (e.g., Vaughan et al., 2013). Samples of the excavated floor material within Schrödinger basin could 347 therefore be used to determine to what extent the melt sheet has differentiated (NRC Goal 6) and would greatly enhance our ability to interpret Apollo samples. The S6 samples would also provide the 
age of the Schrödinger impact event and, therefore, constrain the end of the basin-forming epoch (NRC Goal 1).

A number of in-situ analysis stations (S27-S30, S34-S36, S41-S44, S48-S50) and sampling stations (S32, S37, S38, S45-S49) are situated within the inner-peak ring smooth floor material (Isip), where the rover will sample and analyze additional Schrödinger melt sheet material. This will provide insights into the vertical and lateral variability of the Schrödinger melt sheet (NRC Goal 6).

The rover then continues to stations S31 and S33 where it will sample a relatively smooth and spectrally FeO-rich unit, previously identified as mare basalt deposits $(E m)$ (Shoemaker et al., 1994; Kramer et al., 2013). At stations S39 and S40, the rover will use in-situ analyses to further study the mare deposits. It is also likely that at stations S34, S37, S38, S41- S43, presumably inner-peak ring smooth floor material (Isip), additional mare material can be sampled and/or analyzed. The lateral distribution of the latter sampling and in-situ analysis stations allows for studying melt sheet processes and the lateral compositional and structural variability of the melt sheet (NRC Goal 6). They will also further constrain the compositional variability of the mare deposits (NRC Goal 2, 3 and 5). The first incontext mare basalt samples from the farside will provide insights into the nearside-farside dichotomy of the lunar surface and could test vital aspects of the lunar magma ocean (LMO) hypothesis, including cumulate overturn and the lateral and vertical extent of the LMO. They will also provide insight into their mantle source depths and delivery mechanism to the surface (NRC Goals 2, 3 and 5).

Fig. 6, 7

At stations S45-47 the rover will obtain three rake samples near two large secondary craters that have been identified to originate from Antoniadi crater and Orientale basin (Shoemaker et al., 1994; Kramer et al., 2013) (Fig. 1b, 2). The physics of ballistic sedimentation suggest that secondary ejecta deposits mostly consist of reworked target material (Oberbeck et al., 1975). In order to assess the likelihood of sampling exotic material within the secondary craters identified along the traverse, the model of Morrison and Oberbeck (1978) was used to calculate the diameter and velocity of ejecta fragments that created the secondary craters in Schrödinger basin, assuming a 45 degree launch angle. For a secondary crater of a given diameter, the ratio of surviving primary material to reworked target material within the ejecta deposit was calculated (Fig. 7). The size-velocity distribution indicates that the fragments that formed the largest secondary craters in Schrödinger were kilometer-scale blocks moving at approximately $0.8-2 \mathrm{~km} / \mathrm{s}$. At these velocities, it is expected that approximately $5-18 \%$ of primary 
Antoniadi material would survive, whereas $<5 \%$ of primary Orientale material would have survived (Fig. 7). Sampling this material has the potential to provide highland material, derived from the Orientale basin, and possibly SPA material, derived from Antoniadi crater (O'Sullivan et al., 2011) (NRC Goal 1).

The traverse then continues along a sinuous rill that is likely associated with the mare volcanism within Schrödinger (Kramer et al., 2013) and a high FeO bluff thought be of volcanic origin (Shoemaker et al., 1994). Sampling at stations S48 and S49, and in-situ analysis at station S50, will provide insights into the nature of these features and can be used to determine the compositional and lateral variability of volcanic deposits within Schrödinger basin (NRC Goal 2, 3 and 5).

At a significant number of stations along both traverses, the rover will sample and/or analyze regolith. These results can be used to address three of the four scientific objectives within NRC (2007) Goal 7. The majority of primary craters along the short traverse are of Eratosthenian or Copernican age based on qualitative assessment of crater degradation (Trask, 1971; the Appendix). These craters could be sampled to more precisely determine the lunar impact flux through time (NRC Goal 1).

The estimated total collected sample mass from the short traverse is $\sim 28.5 \mathrm{~kg}$ and will address 21 individual investigations identified by NRC (2007), corresponding to $68 \%$ of the remaining objectives. If the experimental package deployed from the second and/or third ascent vehicle landing includes a seismometer, the lunar interior structure and crater formation processes could also be explored (NRC Goal 1 and 6). Sampling and in-situ stations for the short traverse are summarized the Appendix.

The short traverse can be completed in $\sim 3.5$ months, assuming the rover is continuously operated during lunar days with a constant rover speed of $0.36 \mathrm{~km} / \mathrm{hr}$ during traversing and without repeated analyses at sampling or in-situ stations (Table 2). If the number of in-situ analyses at each station is extended to three analyses per type of in-situ analysis it would take the rover $\sim 6$ months to complete the traverse. This would correspond to a $90 \%$ and $83 \%$ time margin on the total 3 year mission duration. If the landings and ascents were scheduled on a fixed 12 month cadence, the traverse can be completed in 25 months, providing a 30\% margin on schedule. Three in-situ analyses per type of in-situ analysis at each station would increase the total traverse time to 26.5 months, corresponding to a $27 \%$ margin.

\subsection{Long traverse}

The long traverse encompasses both the inner- and outer-peak ring zone of Schrödinger basin and also traverses 6 geological terrains (Fig. 8, 9). It measures $291 \mathrm{~km}$ in length and includes 66 stations (including the stations near the southern basin wall proposed by Hurwitz and Kring, 2015). Samples 
412

would be collected at 16 of these stations. The other stations are in-situ analysis stations that are required to provide sufficient geological context for the returned samples (the Appendix).

Stations S1-S14 and landing site 1 of the long traverse are identical to the short traverse and will, thus, sample the three spectrally distinct crustal lithologies from the peak ring (S2, S3, S5), Schrödinger melt sheet material (S8) and pyroclastic material $(\mathrm{S} 1, \mathrm{~S} 14)$. In-situ analyses will be performed on peak ring lithologies (stations S4, S6) and pyroclastic material (stations S9-S13, L1-L2) and will help to constrain the lateral variability of pristine lunar crustal material and pyroclastic material.

In the south the traverse crosses inner-peak ring smooth floor material (isip), a zone of secondary crater fields associated with Orientale basin $(I s c)$ and smooth outer-peak ring floor material (Isop) (Kramer et al., 2013). The rover will perform in-situ analyses on smooth inner-peak ring floor material at stations L6-L8 and will characterize the existence and lateral extent of melt sheet differentiation (NRC Goal 6). Sampling stations L12A/L12B, L25 and L30 are located within the secondary crater field and provide the opportunity to sample surviving exotic material from Antoniadi crater and/or Orientale basin (Kramer et al., 2013; Fig. 7). Additional in-situ analyses will be performed (Stations L3-L5, L9-L15, L21-L25, L26-32, L37-L38) along the traverse to additionally constrain the occurrence and composition of exotic material within Schrödinger basin. The lateral and vertical distribution of stations along this area is suitable for determining the extent of lateral and vertical mixing of local and ejecta material (NRC Goal 6). In-situ analyses at these stations can also be used to constrain the composition of the underlying smooth outer-peak ring floor material (isop), providing insights into the lateral and compositional variability of Schrödinger melt sheet and, therefore, in melt sheet processes (NRC Goal 6). Samples from stations L12A/L12B, L25 and L30 will also provide an absolute age of the Schrödinger impact event (NRC Goal 1).

Sampling stations L16 and L19 are located near the wall slump in the south-eastern part of the peak ring. Coverage of $\mathrm{M}^{3}$ data suggests the presence of olivine-bearing, pyroxene-bearing and anorthositic lithologies. Sampling at these stations combined with in-situ analyses (Stations L17, L18 and L20) will provide additional insights into the lateral and vertical variability of the lunar crust within the Schrödinger basin (NRC Goals 2 and 3).

In the third section of the long traverse, the rover will have an opportunity to study the smooth hummocky floor material unit (Ish) (Stations L33-L41, L50, L51) identified as the most Mg-rich norite floor unit within Schrödinger (Kramer et al., 2013). This will provide insights into the compositional range of the Schrödinger melt sheet and the occurrence and/or extent of melt sheet differentiation (NRC Goal 6). 
Close to the final landing site, there will be an opportunity to sample material from the southern wall (Iw) (stations L45, L46, L47 as suggested by Hurwitz and Kring (2015), or alternatively, stations L43, L44, L46 and L48 based on this study). A recent study of Hurwitz and Kring (2015) suggest the FeO-rich signature that is thought to represent an SPA impact melt component in Schrödinger wall outcrops and floor material extends from the eastern to the south-eastern wall of Schrödinger basin, with estimates up to $6-8 \%$ of SPA material. Compositional $\mathrm{M}^{3}$ spectra of low-Ca pyroxene in the southern basin wall has been interpreted to indicate the material has a noritic composition (Kramer et al., 2013).

Sampling SPA material would provide an age of the SPA basin-forming event and, therefore, would anchor the early Earth-Moon impact flux (NRC Goal 1). The results from in-situ analysis stations L38-L42 and L49 will be used to additionally constrain the composition of SPA material and to provide geological context of the returned samples. Analyses of regolith along the base of the southern wall could also shed light on the physical properties of ancient regolith (NRC Goal 7).

Crater degradation states of $>10 \mathrm{~m}$ craters along the traverse suggest the majority are of Eratosthenian and Copernican age using the qualitative descriptions of Trask (1971) (the Appendix). Samples of this material can be used to additionally constrain the lunar impact flux through time. The long traverse would collect a total sample mass of $29.5 \mathrm{~kg}$ (the Appendix) and can address a significant amount (65\%) of the remaining individual investigations identified in the NRC (2007) report.

Using the ConOps from Table 2 it is expected that the traverse can be completed within $~ 5.5$ months, which allows for one GRS, APXS and MI analysis and one panorama view at each station. Repeating the latter analyses three times at each station would extend total traverse time to $~ 7$ months, providing $85 \%$ and $80 \%$ margin on both traverse times relative to a 3 year mission duration. If the landings and ascents were scheduled on a fixed 12 month cadence, the traverse can be completed in $\sim 26$ months, providing $28 \%$ margin. The total traverse time is increased to $\sim 27$ months if each analysis is repeated 3 times, corresponding to a $25 \%$ margin on the total 3 year mission duration.

473 optimal mission start dates and to further constrain the times necessary to complete each traverse. This 474 would be especially important along the south-eastern portion of the peak ring. When rover 475 specifications have been confirmed, the rover capabilities (e.g., speed, need to hibernate, and 
communication data rates) and instrumentation payload should be reassessed. The effect of these changes on ConOps times should then be taken into account to further evaluate traverse times.

Several bench craters have been identified along the traverse, which would aid in estimation of the regolith thickness along the traverses. $\mathrm{A} \mathrm{TiO}_{2}$ map would be useful to investigate the nature of the pyroclastic and mare deposits in more detail. The traverses proposed in this study have unique subset routes and, therefore, address different objectives and the possibility of combining both traverses should be assessed given the time margin for completing the latter traverses.

\section{Conclusions}

It has been shown that a long duration, human-assisted robotic mission to the Schrödinger basin can address all 7 of the remaining lunar science concepts as determined by the NRC (2007). Two robotic traverses with sample return capabilities within Schrödinger basin have been constructed for a 3 year mission duration within the HERACLES mission architecture (Landgraf et al., 2015). Both the short- ( 207 $\mathrm{km}$ ) and long ( $291 \mathrm{~km}$ ) traverse accomplish many of the same objectives, but subsets of each traverse are also unique and, therefore, will address different scientific objectives. The trafficability of the Schrödinger pyroclastic deposits was assessed and suggests the vent could be explored for ISRU potential. The proposed traverses would address the majority (>61-65\%) of the individual investigations identified in the NRC (2007) report. Notional ConOps suggests the short and long traverse can be completed within $\sim 3$ and $\sim 5.5$ months, providing a $\sim 91 \%$ and $\sim 85 \%$ margin relative to a 3 year mission duration. If the landings and ascents were scheduled on a fixed 12 month cadence, the short and long traverses are expected to be completed within $\sim 24.5$ and $\sim 26$ months, giving a margin of $~ 32 \%$ and $\sim 28 \%$. The selected sample stations and notional ConOps suggest both traverses are highly attractive for long-term robotic exploration of the lunar surface from both a scientific and exploration science point of view.

\section{Acknowledgements}

This work was carried out through the 2015 Lunar Exploration Summer Intern Program hosted by the Lunar and Planetary Institute (LPI). This research was supported in part by NASA Solar System Exploration Research Virtual Institute contract NNA14AB07A (David A. Kring PI). We thank the staff at LPI for their help and support throughout the internship. LPI Contribution No. \#\#\#.

\section{References}


Arvidson, R.E., May, L. Planetary Science Decadal Survey Mars 2018 MAX-C Caching Rover. NASA mission concept study, 2010.

Barnouin-Jha, O.S., Barnouin-Jha, K., Cheng, A.F., Willey, C., Sadilek, A. Sampling a Planetary Surface with a Pyrotechnic Rock Chipper. IEEE Aerospace Conference Proceedings. Paper 1102, 2004.

Bunte, M.K., Porter, S., Robinson, M.S. A sortie mission to Schrödinger Basin as reconnaissance for future exploration. In: Garry, W. B., Bleacher, J. E. (Eds.), Analogs for Planetary Exploration. The Geological Society of America Special Paper 483. Boulder, CO, pp. 533-546, 2011.

Burns, J.O., Kring, D.A., Hopkins, J.B., Norris, S., Lazio, T.J. W., Kasper, J. A lunar L2-Farside exploration and science mission concept with the Orion multi-purpose crew vehicle and a teleoperated lander/rover. Adv. Space. Res. 52, 306-320, 2013.

Carrier, W.D. III, Olhoeft, G.R., Mendell, W. Physical Properties of the Lunar Surface. In: Lunar Sourcebook, G.H. Heiken, D.T. Vaniman, and B.M. French (eds.), Cambridge University Press, Cambridge, 1991.

Cintala, M. J., Grievem R. A. F. Scaling impact melting and crater dimensions: Implications for the lunar cratering record. Meteorit. Planet. Sci. 33, 889-912, 1998.

Craft, J., Wilson, J., Chu, P., Zacny, K., Davis, K. Percussive digging systems for planetary research. In: IEEE Aerospace Conf., Big Sky MT, 2010.

Crawford, I.A., Anand, M., Cockell, C.S., Falcke, H., Green, D.A., Jaumann, R., Wieczorek, M.A. Back to the Moon: the scientific rationale for resuming lunar surface exploration. Planet. Space. Sci. 74, 3-14, 2012.

Delano, J. Chemistry and liquidus phase relations of Apollo 15 red glass: Implications for the deep lunar interior. Proc. Lunar Planet. Sci. Conf. 11 ${ }^{\text {th }}$, pp. 251-288, 1980.

Gaddis, L.R., Staid, M.I., Tyburczy, J.A., Hawke, B.R., Petro, N.E Compositional analyses of lunar pyroclastic deposits. Icarus 161, 262-280, 2003.

Green, D. H., Ringwood, A. E. Significance of a primitive lunar basaltic composition present in Apollo 15 soils and breccias. Earth Planet. Sci. Lett. 19, 1-8, 1973.

Hauri, E.H., Saal, A.E., Rutherford, M.J., Van Orman, J.A. Water in the Moon's interior: Truth and consequences. Earth Planet. Sci. Lett. 252-264, 2015.

Hiesinger, H., Head, J., Wolf, U., Jaumann, R., Neukum, G. Age and stratigraphy of lunar mare basalts: A synthesis. Spec. Pap. Geol. Soc. Am. 477, 1-51, 2011. 
Houston, W.N., Hovland, H.J., Mitchell, J.K. Lunar Soil Porosity and Its Variation as Estimated from Footprints and Boulder Tracks. Proc. 3rd Lunar Sci. Conf., vol. 3, MIT Press (Cambridge, Mass.), pp. 3255-3263, 1972.

Hovland, H.J., Mitchell, J.K. Friction angle of lunar surface soils estimated from boulder tracks: Space Sciences Laboratory, Lunar Surface Engineering Properties Experiment Definition, Second Quarterly Report, Univ. of California, 117 p, 1969.

Hurwitz, D.M., Kring, D.A. Potential sample sites for South Pole-Aitken basin impact melt within the Schrödinger basin. Earth Planet. Sci. Lett. 427, 31-36, 2015.

Immer, C., Lane, J., Metzger, P., Clements, S. Apollo video photogrammetry estimation of plume impingement effects. Icarus 214, 46-52, 2011.

Johnson, J.B., Mungas, G.S., Zacny, K., Albert, D.G., Banerdt, B., Buehler, M., Elphic, R.C., Lambert, J., Sturm, M., Johnson, K. Lunar and Planetary Science Conference XL. Abstract 1987, 2009.

Kramer, G.Y., Kring, D.A., Nahm, A.L., Pieters, C.M. Spectral and photogeologic mapping of Schrödinger Basin and implications for post-South Pole-Aitken impact deep subsurface stratigraphy. Icarus 223, 131-148, 2013.

Kring, D.A., Durda, D. D. A Global Lunar Landing Site Study to Provide the Scientific Context for Exploration of the Moon. LPI Contribution No. 1694, Lunar and Planetary Institute, Houston, TX, 688p, 2012.

Kring, D.A., Kramer, G.Y., Potter, R.W.K. Interpreting the depth of origin of the Schrödinger peak ring and implications for other impact basins. Large Meteorite Impacts and Planetary Evolution V. Abstract 3069, 2013.

Kring, D. A., Kramer, G. Y., Potter, R. W. K. Interpreting the depth of origin of the Schrödinger peak ring and implications for other impact basins. Large Meteorite Impacts and Planetary Evolution V. Abstract 3069, 2013.

Kring, D.A. Production of volatiles at lunar pyroclastic volcanic vents. In: Annual Meeting of the Lunar Exploration Analysis Group. Abstract 3056, 2014.

Kring, D.A., Kramer, G.Y., Bussey, D.B., Hurley, D.M. Prominent volcanic source of volatiles in the South Polar Region of the Moon. In: Annual Meeting of the Lunar Exploration Analysis Group. Abstract 3057, 2014.

Kumar, P. S., Sruthi, U., Krishna, N., Lakshmi, K. J. P., Menon, R., Amitabh, B., Krishna, G., Kring, D. A., Head, J. W., Goswami, J. N., Kiran Kumar, A. S. Recent shallow moonquake and impact-triggered 
boulder falls on the Moon: New insights from the Schrödinger basin. J. Geophys. Res.: Planets 121, 147-179, 2016.

571

Landgraf, M., Carpenter, J., Sawada, H. HERACLES Concept: An International Lunar Exploration

$572 \quad$ Architecture Study. Lunar Exploration Analysis Group. Abstract 2039, 2015.

573 Loftin, K., Griffith, C.T., Kidd, R., Niedholdt, E., Kibelka, G., Wright, K. Integration and Ruggedization of a

574 Commercially Available Gas Chromatograph and Mass Spectrometer (GCMS) For The Resource

575 Prospector Mission (RPM). Harsh Environment Mass Spectrometry Workshop presentation, 2013.

576 Longhi, J., Walker, D., Grove, T. L., Stolper, E. M., Hays, J. M. The petrology of the Apollo 17 mare basalts.

577 Proc. Lunar Sci. Conf. $5^{\text {th }}$, pp. 447-469, 1974.

578 Lucey, P.G., Blewett, D.T., Hawke, B.R. Lunar iron and titanium abundance algorithms based on final 579 processing of Clementine ultraviolet-visible images. J. Geophys. Res. 105 (E8), 20297-20305, 2000.

580 NASA Space Science Data Center. Document 1970-095A, 1970.

$581 \quad$ NASA Space Science Data Center. Document 1973-001A, 1973.

582 Malin, M.C., Bell, J.F., Cameron, J., Dietrich, W.E., Edgett, K., Hallet, B., Herkenhoff, K.E., Lemmon, M.T.,

583 Parker, T.J., Sullivan, R.J., Sumner, D.Y., Thomas, P.C., Wohl, E.E., Ravine, M.A., Caplinger, M.A. and 584 Maki, J.N. The mast cameras and Mars descent imager (MARDI) for the 2009 Mars Science Laboratory. Lunar and Planetary Science Conference XXXVI. Abstract 1214, 2005.

Martin, D. J. P., McDonald, F. E., Steenstra, E. S., Paisarnsombat, S., Venturino, C. S., O’Hara, S., CalzadaDiaz, A., Leader, M. K., Bottoms, S., Klaus, K. K., Hurwitz-Needham, D., Kring, D. A. A long duration human-assisted robotic sample return mission to the Schrödinger basin part 2: traversing towards the basin wall. Lunar and Planetary Science Conference 47. Abstract 1468, 2016.

McDonald, F. E., Martin, D. J. P., Steenstra, E. S., Paisarnsombat, S., Venturino, C. S., O'Hara, S., Calzada-

Diaz, A., Leader, M. K., Bottoms, S., Klaus, K. K., Hurwitz-Needham, D., Kring, D. A. A long duration human-assisted robotic sample return mission to the Schrödinger basin part 1: traversing the basin center. Lunar and Planetary Science Conference 47. Abstract 1464, 2016.

Meyer, C., Jr., McKay, D.S., Anderson, D.H., Butler, P., Jr. The source of sublimates on the Apollo 15 green and Apollo 17 orange glass samples. Proc. Lunar Sci. Conf. $6^{\text {th }}$, p. 1673-1699, 1975.

596 Mitchell, J.K., Houston, W.N., Scott, R.F., Costes, N.C., Carrier, W.D., Bromwell, L.G. Mechanical 597 properties of lunar soil: Density, porosity, cohesion, and angle of internal friction. Proc. Lunar Sci. 598 Conf. Proc. $3^{\text {rd }}$, GCA, 3, 3235-3253, 1972. 
Mitchell, J.K , Carrier, III, W.D., Costes, N.C., Houston, W.N., Scott, R.F., Hovland, H.J. Chapter 8: Soil mechanics. In: Apollo 17 Preliminary Science Report. Scientific and Technical Information Office, NASA, Washington D.C., 1973.

Moore, H.J. Estimates of the mechanical properties of lunar surface using tracks and secondary impact craters produced by blocks and boulders (No. 70-229). US Dept. of the Interior, Geological Survey, 65 p, 1970.

Morrison, R.H., Oberbeck, V.R. A composition and thickness model for lunar impact crater and basin deposits. Lun. Planet. Sci. Conf. Proc. $9^{\text {th }}, 3763-3785,1978$.

Myrick, T.M., Davis, K., Wilson, J. Rock Abrasion Tool. 37 ${ }^{\text {th }}$ Aerospace Mechanisms Symposium, pp. 277290, 2004.

Myrick, T.M., Pham, T.T., Kalanick, M.F. Rock Core Capture and Caching Technique. In: International Workshop on Instrumentation for Planetary Missions. LPI Contribution No. 1683, p. 1118, 2012.

National Research Council. The scientific context for exploration of the Moon, Final Report. National Academies Press, Washington, DC, pp. 120, 2007.

O'Sullivan, K.M., Kohout, T., Thaisen, K.G., Kring, D.A. Calibrating several key lunar stratigraphic units representing 4 b.y. of lunar history within Schrödinger basin, in: Williams, D. A., Ambrose, W. (Eds), Recent Advances in Lunar Stratigraphy. Geological Society of America Special Paper 477, Boulder, CO., pp. 117-127, 2011.

Oberbeck, V.R., Hörz, F., Morrison, R.H., Quaide, W.L., Gault, D.E. On the origin of the lunar smoothplains. The Moon, 12(1), 19-54, 1975.

Paulsen, G., Zacny, K., Steele, A., Conrad, P., Chu, P., Hedlund, M., Craft, J., McCarthy, T., Schad, C. Demonstration of the Acquisition and Caching for the Mars Sample Return Missions. Lunar and Planetary Science Conference XLIII Abstract 1151, 2012.

Petrov, G. I. Investigation of the Moon with the Lunokhod 1 space vehichle. In: COSPAR Space Research XII, pp. 1-12. Akademie-Verslag, Berlin, 1972.

Potts, N.J., Gullikson, A.M., Curran, N.M., Dhaliwal, J.K., Leader, M.K., Rege, R.N., Klaus, K.K., Kring, D.A. Robotic traverse and sample return strategies for a lunar farside mission to the Schrödinger basin. Adv. Space Res. 55, 1241-1254, 2015.

Pratt, W., Alkalai, L., Buxton, C., Drever, M., Hall, S., Hopkins, J.B., Ringelberg, J., Scott, A. Humanassisted sample return from the Moon and Mars using the Orion spacecraft. International Astronautical Congress, IAC-13-A5.1.7, 2014. 
630

631

632

633

634

635

636

637

638

639

640

641

642

643

644

645

646

647

648

649

650

651

652

653

654

655

656

657

658

659

660

661

Rieder, R., Gellert, R., Bruckner, J., Klingelhofer, G., Dreibus, G., Yen, A., Squyres, S.W. The new Athena alpha particle X-ray spectrometer for the Mars Exploration Rovers. J. Geophys. Res.: Planets 108, 8066-8078, 2003.

Rutherford, M.J., Papale, P. Origin of basalt fire-fountain eruptions on Earth versus the Moon. Geology 37, 219-222, 2009.

Seeni, A., Schäfer, B., Hirzinger, G. Robot mobility systems for planetary surface exploration: state-ofthe-art and future outlook: a literature survey. In Thawar, T. Arif (Eds.), Aerospace Technologies Advancements, Chapter 10, pp. 189-208, ISBN: 978-953-7619-96-1, 2010.

Shearer, C., Neal, C., Borg, L., Jolliff, B., Papanastassiou, D., Treiman, A., Floss, R., Rutherford, M., Norman, M., Farquhar, J. Analysis of lunar sample mass capability for the lunar exploration architecture. Unpublished white paper, 12p, posted May 2007 by the Curation and Analysis Planning Team for Extraterrestrial Materials (CAPTEM). http://www.Ipi.usra.edu/captem/.

Shearer, C., Tahu, G. Lunar Polar Volatiles Explorer (LPVE). NASA Mission Concept Study, 2010.

Shoemaker, E. M., Robinson, M.S., Eliason, E.M. The South Pole Region of the Moon as Seen by Clementine. Science 266, 1851-1854, 1994.

Stolper, E. M. Apollo 15 green glass. A.B. thesis, Harvard University. 178 pp, 1974.

Terzaghi, K. Theoretical soil mechanics. New York, John Wiley and Sons, Inc., p. 509, 1948.

Tian, B. Y., Poole, W. D., Garber, J. M., French, R. A., Smith, P. H., Barnes, J. J., Kring, D. A. Landing sites optimized for geophysical studies of the structure and thermal state of the lunar interior. Lunar Planetary Science Conference XLIV. Abstract 1629, 2013.

Trask, N.J. Geologic comparison of mare materials in the lunar equatorial belt, including Apollo 11 and Apollo 12 landing sites. U.S. Geol. Surv. Prof. Pap., 750D, 138-148, 1971.

Vaughan, W.M., Head, J.W., Wilson, L., Hess, P.C. Geology and petrology of enormous volumes of impact melt on the Moon: A Case study of the Orientale basin impact melt sea. Icarus 223, 749-765, 2013.

Venturino, C.S., Martin, D. J. P., McDonald, F. E., Paisarnsombat, S., Steenstra, E. S., O'Hara, S., CalzadaDiaz, A., Bottoms, S., Leader, M. K., Klaus, K. K., Gregg, T. K. P., Kring, D.A. Lunar pyroclastic soil mechanics and trafficability in the Schrödinger basin. Lunar Planetary Science Conference 47. Abstract 1676, 2016.

Walker, D., Kirkpatrick, R. J., Longhi, J., Hays, J. F. Crystallization history of lunar picritic basalt sample 12002: Phase equilibria and cooling rate studies. Geol. Soc. Am. Bull. 87, 646-656, 1976.

Wieczorek, M., Mimoun, D., Baratoux, D., Bouley, S., Cecconi, B., Collins, G., Cook, A., Crawford, I., Dehant, V., Falcke, H., Garcia, R., Giardini, D., Grimm, R., Grott, M., Grygorczuk, J., Gurtvis, L., Ivanov, 
B., Jaumann, R., Josset, J-L., Klein-Wolt, M., Kletetschka, G., Koopmans, L., Langlais, B., Lawrence, D., Lognonne, P., Margonis, A., Meslin, P-Y., Neal, C., Oberst, J., Ripka, P., Schmitz, N., Spohn, T., Werner, S., Zarka, P. Farside: A mission to the farside of the Moon. ESA mission proposal, 2015.

Wetzel, D.T., Hauri, E.H., Saal, A.E., Rutherford, M.J. Carbon content and degassing history of the lunar volcanic glasses. Nature Geoscience doi:10.1038/ngeo2511, 2015.

Wilhelms, D., Howard, K., Wilshire, H. Geological Map of the South Side of the Moon. U.S. G.S. Miscellaneous Investigative Series Map I-1162, 1979.

Zacny,, K., Craft, J., Hedlund, M., Wilson, J., Chu, P., Fink, P., Mueller, R., Galloway, G., Mungas, G. Novel Approaches to Drilling and Excavation on the Moon. American Institute Of Aeronautics and Astronautics Conference. Abstract 2009-6431, 2009.

Zacny, K., Chu, P., Paulsen, G., Craft, J. Core acquisition and caching for the 2020 Mars mission. Lunar and Planetary Science Conference XLIV. Abstract 1331, 2013.

Zacny, K., Conrad, P., Mahaffy, W., Brinckerhoff, W., Steele, A., Blake, D., Anderson, S. Concepts and Approaches for Mars Exploration. Abstract 4282, 2012.

\section{Figure captions}

Fig. 1. Maps of Schrödinger basin showing (A) the WAC image and (B) the WAC image with overlain geological map of Kramer et al. (2013) with brown $(E p)=$ pyroclastic material, red $(E m)=$ inter-basin mare material, purple $(I s c)=$ secondary crater field, dark purple $(I m p)=$ impact melt ponds, from light to dark blue: $I s i p=$ smooth inner-peak ring floor material, $I s d s=$ spectrally distinct smooth floor material, $I s o p=$ smooth outer-peak ring floor material, $I s h=$ smooth hummocky floor material, lipr $=$ inter-peak ring floor material, Irh = rough hummocky floor material, light brown $(I w)=$ wall material, horizontally dashed $=$ wall slump, vertically dashed $=$ peak ring slump and yellow $(p N p r)=$ peak ring material .

Fig. 2. Schematic overview of Schrödinger basin showing the major geological units and surface morphology with a topographic, vertical exaggeration of $\sim 3$. Range of pyroclastic source depths based on Delano (1980), Stolper (1974), Green and Ringwood (1973) and range of mare basalt source depths based on Walker et al. (1976) and Longhi et al. (1974).

Fig. 3. The identified boulders and trails (detail of NAC images M141351170LE, M141357955LE) within the pyroclastic material that were used to determine the bearing capacity of the pyroclastic deposits. 
Fig. 4. Short traverse. Maps were generated in $\operatorname{ArcGIS}^{\circledR}$ using WAC imagery (A) The short traverse overlain by the geological map of Kramer et al. (2013). The three landing sites are indicated with yellow filled circles, in-situ analysis stations with open red circles and sampling sampling stations with red filled circles. Brown $(E p)=$ pyroclastic material, red $(E m)=$ inter-basin mare material, purple $(I s c)=$ secondary crater field, light blue $($ Isip $)=$ smooth inner-peak ring floor material, dark blue (lipr) = inter-peak ring floor material and yellow $(p N p r)=$ peak ring material. (B) The short traverse overlain by the slope map based on LOLA data.

Fig. 5. Views along the short traverse. The $3 D$ views were created using LRO NAC images overlain on LOLA topography data using ArcScene $(\mathrm{C}$. (A) Oblique view of the stations along the peak ring area based on LRO NAC images M108293032LE-RE, M110650294LC-RE, M113006586RC, M167289673LC, M169650959LC and M174368352RC (B) Boulder identified at station S5. (C) Oblique view of the fracture north of the peak ring area. (D) Top down view of the fracture at station S6. (E) Station S32 with a $5 \mathrm{~m}$ boulder, diameter of crater is $220 \mathrm{~m}$.

Fig. 6. Schematic cross-section of the pyroclastic vent in Schrödinger basin based on LOLA topographical data and surface geological units from Kramer et al. (2013). It shows a volatile-driven fire-fountain type of eruption, upon which the melt droplets are quenched to glass bead and subsequently coated by condensation of volatile-rich vapors. Source depth estimates based on Delano (1980), Stolper (1974) and Green and Ringwood (1973).

Fig. 7. Plot showing the estimated primary material within the secondary ejecta deposit (in wt.\%) as a function of the secondary crater diameter.

Fig. 8. Long traverse. Maps generated in ArcGISC using WAC imagery. The three landing sites are indicated with yellow filled circles, in-situ analysis stations with open red circles and sampling stations with red filled circles. The dashed line is an optional route close to the volcanic vent. (A) The long traverse overlain by the geological map of Kramer et al. (2013) with brown $(E p)=$ pyroclastic material, purple $(I s c)=$ secondary crater field, from lighter to darker blue: Isip $=$ smooth inner-peak ring floor material, lipr = inter-peak ring floor material, $I s h=$ smooth hummocky floor material, light brown $(I w)=$ wall material, horizontally dashed $=$ wall slump and yellow $(p N p r)=$ peak ring material. $(\mathrm{B})$ The long 
726 traverse overlain by the slope map based on LOLA data and corresponding elevation profile of the long 727 traverse.

729 Fig. 9. Views from the long traverse. The 3D views were created using LRO NAC images overlain on LOLA 730 topography data using ArcScene $C$. (A) View inside the pyroclastic vent from the long traverse. (B-C) 731 Overview of station L19 showing a $\sim 1.1 \mathrm{~km}$ boulder track. The boulder originated from an outcrop 732 higher up slope. (D) Overview of the SE wall area and the stations identified within this area. (E) The SE 733 wall area overlain by $\mathrm{M}^{3}$ data (Kramer et al., 2013). (F) Station L44 showing outcrops of noritic lithologies 734 based on $\mathrm{M}^{3}$ data (Kramer et al., 2013). (G) Station L48 situated close to a boulder field of pyroxene735 bearing anorthositic material, based on $\mathrm{M}^{3}$ data (Kramer et al., 2013). 


\section{APPENDIX A.}

Appendix for "Analyses of Robotic Traverses and Sample Sites in the Schrödinger basin for the HERACLES Human-Assisted Sample Return Mission Concept" by E.S. Steenstra, D.J.P. Martin, F.E. McDonald, S. Paisarnsombat, C. Venturino, S. O'Hara, A. Calzada-Diaz, M.K. Leader, K.K. Klaus, W. van Westrenen, D. H. Needham, D.A. Kring.

\section{Details on traverse stations}

Tables S.1. and S.2. list the sampling stations that were identified along the short and long traverse, respectively. Included are the location, type of sample and mass, type of in-situ analyses and scientific goals that can be addressed at the identified stations along each traverse. The amount of sampling stations were based on the assumption of a notional baseline of $<30 \mathrm{~kg}$ of total returned sample mass.

\section{Calculations of sample mass capabilities of sample container spheres}

The maximum sample mass that can be returned from the lunar surface is constrained by the volume of the sample transport container that is required for exchanging the samples from the lander to the exploration Deep Space Habitat (eDSH) and subsequently to the Orion crew vehicle. Current designs include spherical sample containers with variable diameters dependent on their mission context (Pratt et al., 2014). However, the technical specifications (e.g., wall thickness) of these containers are not known. We therefore consider a simple scenario assuming spheres with variable internal diameters and calculate the volumes that would be required for various sample suites (Fig. S.1). Because of the current uncertainty in the sample mass that may be returned to Earth, an arbitrary maximum sample mass of 10 $\mathrm{kg}$ per ascent was considered in this study. This is a baseline limit given the lander ascent mass capability presented in this work and additional returned samples would significantly increase the overall productivity of a robotic mission to Schrödinger basin. The different lunar lithologies exhibit a wide range of densities and therefore we assume the associated densities of $3.0-3.3 \mathrm{~g} / \mathrm{cm}^{3}$ for basaltic lithologies (Kiefer et al., 2012), 2.0-2.6 g/ $\mathrm{cm}^{3}$ for impact melt breccias (Warren, 2001; Macke et al., 2012), 1.3-1.8 g/ $\mathrm{cm}^{3}$ for lunar regolith (Mitchell et al., 1972) and 2.6-3.7 g/ $\mathrm{cm}^{3}$ for homogeneous rocks that include anorthosites, norites and dunites. We then calculated the mass capability of the sample container sphere that would be required to accommodate the sampled lithologies along each section of the traverse (Table S.3, Fig. S.1).

\section{Calculation of ascend vehicle payload capabilities}

To assess how much sample mass can be returned from the lunar surface, we designed a baseline, reusable ascent vehicle based on the dimensions of the JPL Mars Ascent Vehicle (MAV). The ascent vehicle has a length of 2.56 meters, a diameter of 0.442 meters, and a mass (with a $30 \%$ contingency) of $80 \mathrm{~kg}$ (Stephenson and Willenberg, 2006; Dux et al., 2011). A maximum $\Delta \mathrm{V}$ of 2,434 m/s was shown to be sufficient for an ascent vehicle to travel from the lunar surface to Orion in an EM-L2 orbit, EM-L2 halo orbit, or distant retrograde orbit (DRO) (Pratt et al., 2014). The proposed traverses in this study were based notional sample payload of $10 \mathrm{~kg}$ per ascent, that has been shown to be the minimum required sample mass that is able to successfully capture important geological samples. We also have shown that this payload is the baseline, and that more returned sample mass would greatly increase the overall productivity of the mission. Four different engines were examined for this ascent vehicle study. Only liquid fuel engines of an appropriate size were selected due to the HERACLES architecture that requires a reusable ascent vehicle. Eqs. (A.1, A.2) were used to calculate the maximum payload for the given $\Delta V$ :

$\Delta V=v_{e} \ln (P M F)$ 
$P M F=\frac{\text { Full Mass }}{\text { EmptyMass }}$

in which $\Delta V$ is the change in velocity $(\mathrm{m} / \mathrm{s}), V_{e}$ is the exhaust velocity $(\mathrm{m} / \mathrm{s})$ and PMF is the propellant mass fraction. Figure S.2 shows the maximum payload as a function of ascent vehicle volume for each engine type. These calculations suggests the MAV has the ability to lift payload far exceeding $10 \mathrm{~kg}$. Additional calculations were then performed to determine the minimum ascent vehicle engine volume that is required to lift off $10 \mathrm{~kg}$ of sample payload from the lunar surface. This requires selection of a certain engine type and type of propellant. The Aestus II, a collaboration between Ottobrunn Space Propulsion Centre and Rocketdyne, seems to be most suited for a reusable ascent vehicle of the size considered in this study. Monomethylhydrazine $(\mathrm{MMH})$ was determined to be the best propellant for storage and refueling due to its relatively high boiling point and low freezing point. Of the engines we considered which use MMH, the Aestus II has the highest ISP and thrust (Table S.4) Propellant storage is also important to consider because of the 3-year mission length of the HERACLES mission concept and the potential for the ascent vehicle to sit on the lunar surface for long periods of time. When the Aestus Il engine is considered, we observe that the initial estimate for the size of the ascent vehicle is larger than required for a $11 \mathrm{~kg}$ payload (10 kg of samples and $1 \mathrm{~kg}$ of packaging). Figure S.3. shows the estimated ascent vehicle dimensions for a wider range of payloads (in this case sample masses).

\section{Qualitative assessment of crater degradation states}

Evaluation of the ages of the sampled primary craters along the traverses is essential for determining the recent (post-Imbrian) impact flux. We therefore assessed the age of small ( $<10 \mathrm{~km}$ diameter) primary craters sampled along the traverse using the crater degradation model of Trask (1971). This model is a simple approach that is based on the various degradation states of primary craters due to space weathering over time. We observe that although both traverses will yield samples from relatively young craters, the medium traverse is expected to provide a wider range of sampled crater ages and potentially better calibration of the post-Imbrian impact flux (Fig. S.4.).

\section{Soil mechanics and rover trafficability}

Figure S.5. shows the boulder tracks which were used in the calculations related to assessment of rover trafficability in the pyroclastic deposits (see main text). Details on the calculations are provided in Tables S.5-S.7.

\section{Communication and returning HD imagery of the lunar surface}

Returning HD imagery is of great importance for the educational and promotional yields of planetary exploration (e.g., the Kaguya mission, Terazono et al., 2009). Here, we assess the possibility of returning $\mathrm{HD}$ imagery from the lunar surface to eDSH, and subsequently from the eDSH to ground stations on Earth.

\subsection{Communication between rover and eDSH}

Communication between the rover and the eDSH is likely to occur through KA band system, which is currently the most feasible way of communication as there is currently no funding for a dedicated farside communications-relay satellite in an Earth-Moon L2 halo orbit (Pratt et al., 2014). Current mission designs require a high data rate from the rover to the EAM that allows for transmitting high quality (HD) imagery and/or video. However, the data transfer rate between the rover and the EAM may be limited to approximately 200-400 kbps at their average separation distance - approximately 60.000 $\mathrm{km}$ from the lunar surface to the EM-L2 halo orbit (Pratt et al., 2014). Direct transmission of 720p HD video would require $\sim 5 \mathrm{mbps}$, far exceeding the estimated data transfer rate. High-definition imagery 
and/or videos must therefore be transferred at much lower speeds. To determine the feasibility of transmitting stored HD imagery and/or video from the rover, knowledge of the communication data rates during different rover operation modes is required. During traversing, the rover-eDSH communications data rate will be $\sim 89 \mathrm{kbps}$ as it requires continuous operation of the two Hazcams and the Ground Penetrating Radar (Table 1, main text). During stationary analyses, data rates will be significantly lower. For example during APXS analysis, the Hazcams and GPR can be turned off allowing for the transfer of HD imagery and/or videos stored on the rover.

\subsection{Communication between eDSH and ground stations on Earth}

For the communication between the eDSH and ground stations on Earth we performed a trade study between KA-band or laser communication. Laser communication has heritage on the Laser Lunar Communication Demonstration (LLCD) on the Lunar Atmospheric and Dust Environment Explorer (LADEE) mission, whereas KA-band communication has heritage on many missions (e.g., Kepler, the Lunar Reconnaissance Orbiter and military satellites). However, improvements in laser communication has been identified as an important technology development for future deep space exploration, because it has the potential to deliver data rates that far exceeds those using KA-band (e.g., Boroson and Robinson, 2014). Laser communication also requires half the power that is used for KA-band (Table S.8.).However, for a robotic mission to the lunar surface the distance between the eDSH and the Earth is insufficiently large for significant delays for KA-band communication. In addition, clouds may have a significant effect on laser communication. For example, thin cloud coverage can potentially reduce the data rate to $77 \mathrm{Mbps}$ (Cornwell et al., 2014). The use of laser communication would also require more ground stations on Earth's then currently available. We conclude that, given the amount of data that would need to be transferred to support HD imagery and the heritage of both types of communication, KA-band is sufficient and less costly for communication between the eDSH and ground stations on Earth.

\section{Supplementary references}

Boroson, D. M., Robinson, B. S. The Lunar Laser Communication Demonstration: NASA's First Step Toward Very High Data Rate Support of Science and Exploration Missions. Space Sci. Rev., 185, 115128, 2014.

Cornwell, D., Boroson, D., Robinson, B., Burianek, D., Murphy, D., Khatri, F. The Lunar Laser Communication Demonstration (LLCD). Presentation to JHU Aerospace Affinity Group. $<$ http://alumni.jhu.edu/sites/default/files/NASA-LasercomTalk-JHU-Aerospace-Affinity-June-11th2014.pdf>, 2014.

Dux, I. J., Huwaldt, J. A., Mckamey, R. S., Dankanich, J. W. Mars Ascent Vehicle Gross Lift-off Mass Sensitivities for Robotic Mars Sample Return. NASA/TM-2011-216968, 2011.

Hurwitz, D. M., Kring, D. A. Potential sample sites for South Pole-Aitken basin impact melt within the Schrödinger basin. Earth Planet. Sci. Lett. 427, 31-36, 2015.

Kiefer, W. S., Macke, R. J., Britt, D. T., Irving, A. J., Consolmagno, G. J. Regional variability in the density of lunar mare basalts and implications for lunar gravity modeling. Lunar and Planetary Science Conference Proceedings. Abstract 1642, 2012.

Kramer, G. Y., Kring, D. A., Nahm, A. L., Pieters, C. M. Spectral and photogeologic mapping of Schrödinger Basin and implications for post-South Pole-Aitken impact deep subsurface stratigraphy. Icarus 223, 131-148, 2013.

Macke, R. J., Kiefer, W. S., Britt, D. T., Irving, A. J., Consolmagno, G. J. Density and Porosity of Apollo Lunar Basalts and Breccias. Lunar and Planetary Science Conference 43. Abstract 1299, 2012.

Mitchell, J. K., Houston, W. N., Scott, R. F., Costes, N. C. Mechanical properties of lunar soil: density, porosity, cohesion, and angle of internal friction. Proceedings of the Third Lunar Science Conference 3235-3253, 1972. 
National Research Council. The scientific context for exploration of the Moon, Final Report. National Academies Press, Washington, DC, pp. 120, 2007.

Pratt, W., Alkalai, L., Buxton, C., Drever, M., Hall, S., Hopkins, J. B., Ringelberg, J., Scott, A. Humanassisted sample return from the Moon and Mars using the Orion spacecraft. $65^{\text {th }}$ IAC, 13-A5.1.7., 2014.

Shearer, C., Neal, C., Borg, L., Jolliff, B., Papanastassiou, D., Treiman, A., Floss, R., Rutherford, M., Norman, M., Farquhar, J., Analysis of lunar sample mass capability for the lunar exploration architecture. Unpublished white paper, 12p, posted May 2007 by the Curation and Analysis Planning Team for Extraterrestrial Materials (CAPTEM). <http://www.lpi.usra.edu/captem/>

Stephenson, D. D., Willenberg, H. J. Mars Ascent Vehicle: Key Elements of a Mars Sample Return Mission. IEEEAC. Abstract 1009, 2006.

Terazono, J., Yoshikawa, M., Wakabayashi, N. Space Education Strategy Using Data Obtained by Lunar and Planetary Missions. Trans. JSASS Space Tech. Japan., 7, Tu_25-Tu_29, 2009.

Trask, N. J. Geologic comparison of mare materials in the lunar equatorial belt, including Apollo 11 and Apollo 12 landing sites. U.S. Geol. Surv. Prof. Pap., 750D, 138-148, 1971.

Warren, P. H. Porosities of lunar meteorites: Strength, porosity, and petrologic screening during the meteorite delivery process. J. Geophys. Res. 106, 10101-10111, 2001.

Willhelms, D. E. The Moon. In: The Geology of the Terrestrial Planets (M. Carr et al., eds.), pp. 107-205. NASA SP-469, 1984. 
Table S.1. Summary of location, type of sample and mass, type of in-situ analyses and scientific goals (NRC, 2007) that can be addressed at the identified stations of the short traverse assuming a notional baseline of $<30 \mathrm{~kg}$ of total returned sample mass

\begin{tabular}{|c|c|c|c|c|c|c|}
\hline & Latitude & Longitude & $\begin{array}{l}\text { Elevation } \\
(\mathrm{m})\end{array}$ & $\begin{array}{l}\text { Lithological } \\
\text { unit }^{1}\end{array}$ & $\begin{array}{l}\text { Sample type } \\
\text { and mass }(\mathrm{g})^{2}\end{array}$ & Scientific goals addressed $^{3}$ \\
\hline Landing site 1 & -75.4050 & 141.1768 & -4733 & & & \\
\hline Station S1 & -75.4907 & 141.3745 & -4723 & Ep & Regolith (2000) & $2 b, 2 d, 5 c, 5 d, 7 b, 7 c$ \\
\hline Station S2 & -75.4906 & 142.0473 & -4541 & $\mathrm{pNpr}$ & Boulder $(500)^{a}$ & $2 a, 3 a, 3 b, 3 c, 3 d$ \\
\hline Station S3 & -75.3983 & 142.1327 & -4520 & $\mathrm{pNpr}$ & Boulder $(500)^{a}$ & $2 a, 3 a, 3 b, 3 c, 3 d$ \\
\hline Station S4 & -75.3651 & 142.1738 & -4465 & $\mathrm{pNpr}$ & Boulder (N/A) & $2 a, 3 a, 3 b, 3 c, 3 d$ \\
\hline Station S5 & -75.2628 & 142.2408 & -4506 & $\mathrm{pNpr}$ & Boulder $(500)^{a}$ & $2 a, 3 a, 3 b, 3 c, 3 d$ \\
\hline Station S6 & -75.1507 & 141.9541 & -4820 & $\mathrm{Ep} / \mathrm{pNpr}$ & Mixed rake (1000) & $2 a, 2 b, 2 d, 3 a, 3 b, 3 c, 3 d,(4 a, 4 b, 4 c), 5 c, 5 d$ \\
\hline Station S7 & -75.2560 & 141.8327 & -4651 & lipr & Boulder (N/A) & $6 c$ \\
\hline Station S8 & -75.3027 & 141.9196 & -4618 & lipr & Boulder $(5000)^{b}$ & $1 \mathrm{a}, 1 \mathrm{c}, 1 \mathrm{~d}, 6 \mathrm{c}$ \\
\hline Station S9 & -75.4149 & 141.4296 & -4740 & Ep & Regolith (N/A) & $2 b, 2 d, 5 c, 5 d, 7 b, 7 c$ \\
\hline Landing site 1 & -75.4050 & 141.1768 & -4733 & & (Total: 9.5 kg) & \\
\hline Station S10 & -75.3602 & 140.9211 & -4706 & Ep & Boulder (N/A) & $2 b, 2 d, 5 c, 5 d, 6 c, 6 d$ \\
\hline Station S11 & -75.3370 & 140.8480 & -4734 & Ep & Regolith (N/A) & $2 b, 2 d, 5 c, 5 d, 6 c, 6 d, 7 b, 7 c$ \\
\hline Station S12 & -75.3121 & 140.4326 & -4590 & Ep & Boulder (N/A) & $2 b, 2 d, 5 c, 5 d, 6 c$ \\
\hline Station S14 & -75.2554 & 140.2323 & -4572 & Ep & Regolith (2000) & $1 d, 2 b, 2 d, 5 c, 5 d, 7 b, 7 c$ \\
\hline Station S15 & -75.1561 & 140.1177 & -4538 & Ep & Boulder (N/A) & $2 b, 2 d, 5 c, 5 d, 6 c$ \\
\hline Station S16 & -75.0817 & 140.1110 & -4586 & Ep & Boulder (N/A) & $2 b, 2 d, 5 c, 5 d, 6 c$ \\
\hline Station S17 & -75.0749 & 140.1027 & -4590 & Ep & Regolith (N/A) & $2 b, 2 d, 5 c, 5 d, 6 c, 7 b, 7 c$ \\
\hline Station S18 & -75.0287 & 140.2267 & -4634 & Ep & Regolith (N/A) & $2 b, 2 d, 5 c, 5 d, 6 c, 7 b, 7 c$ \\
\hline Station S19 & -74.9926 & 140.2379 & -4654 & Ep & Regolith (N/A) & $2 b, 2 d, 5 c, 5 d, 6 c, 7 b, 7 c$ \\
\hline Station S2O & -74.9580 & 140.1913 & -4676 & Ep & Regolith (N/A) & $2 b, 2 d, 5 c, 5 d, 6 c, 7 b, 7 c$ \\
\hline Station S21 & -74.9087 & 140.0887 & -4746 & Ep & Regolith (N/A) & $2 b, 2 d,(4 a, 4 b, 4 c), 5 c, 5 d, 7 b, 7 c$ \\
\hline Station S22 & -74.8699 & 139.1497 & -4664 & Ep & Regolith (N/A) & $2 b, 2 d, 5 c, 5 d, 6 c, 7 b, 7 c$ \\
\hline Station S23 & -74.8453 & 139.0352 & -4660 & Ep & Boulder (N/A) & $2 b, 2 d, 5 c, 5 d, 6 c$ \\
\hline Station S24 & -74.8570 & 138.7690 & -4650 & Ep & Regolith (2000) & $1 d, 1 e, 2 b, 2 d, 5 c, 5 d, 6 c, 7 b, 7 c$ \\
\hline Station S25 & -74.7741 & 138.8835 & -4710 & Ep & Boulder (N/A) & $2 b, 2 d, 5 c, 5 d, 6 c$ \\
\hline Station S26 & -74.5854 & 138.7655 & -4767 & Ep & GPR (N/A) & $5 c, 7 b, 7 c$ \\
\hline Station S27 & -74.5501 & 138.7259 & -4801 & Ep/Isip & GPR (N/A) & $5 c, 7 b, 7 c$ \\
\hline Station S28 & -74.5186 & 138.6371 & -4804 & Ep/Isip & GPR (N/A) & $5 c, 7 b, 7 c$ \\
\hline Station S31 & -73.8455 & 137.5857 & -4835 & $\mathrm{Em}$ & Regolith (500) & $2 b, 2 d, 3 a, 3 b, 5 a, 5 b, 5 d, 7 b, 7 c$ \\
\hline Station S32 & -73.9664 & 136.4695 & -4775 & Isip & Boulder $(5000)^{b}$ & $1 a, 1 c, 1 e, 6 a, 6 c, 6 d$ \\
\hline Station S33 & -74.1203 & 134.7569 & -4784 & Em & Regolith (500) & $2 b, 2 d, 3 a, 3 b, 5 a, 5 b, 5 d, 7 b, 7 c$ \\
\hline Landing site 2 & -74.0760 & 134.5498 & -4778 & & (Total: 10.0 kg) & \\
\hline Station S34 & -74.0478 & 133.8572 & -4776 & Em/Isip & Boulder (N/A) & $2 b, 2 d, 3 a, 3 b, 5 a, 5 b, 5 d$ \\
\hline Station S35 & -74.0383 & 133.6015 & -4782 & Isip & Boulder (N/A) & $6 a, 6 c, 6 d$ \\
\hline Station S36 & -74.0420 & 133.5345 & -4792 & Isip & Boulder (N/A) & $6 a, 6 c, 6 d$ \\
\hline Station S37 & -74.0455 & 133.5285 & -4796 & Em/Isip & Boulder (500) & $2 b, 2 d, 3 a, 3 b, 5 a, 5 b, 5 d, 6 a, 6 c, 6 d$ \\
\hline Station S38 & -74.0520 & 133.4926 & -4805 & Em/Isip & Boulder (500) & $2 b, 2 d, 3 a, 3 b, 5 a, 5 b, 5 d, 6 a, 6 c, 6 d$ \\
\hline Station S39 & -74.0743 & 133.4241 & -4811 & $\mathrm{Em}$ & Regolith (N/A) & $2 b, 2 d, 3 a, 3 b, 5 a, 5 b, 7 b, 7 c$ \\
\hline Station 540 & -74.0941 & 133.3957 & -4810 & Em & Boulder (N/A) & $2 b, 2 d, 3 a, 3 b, 5 a, 5 b$ \\
\hline Station 541 & -74.1973 & 133.3561 & -4786 & Em/Isip & Boulder (N/A) & $2 b, 2 d, 3 a, 3 b, 5 a, 5 b, 6 a, 6 c, 6 d$ \\
\hline Station 542 & -74.2370 & 132.9933 & -4775 & Em/Isip & Regolith (N/A) & $2 b, 2 d, 3 a, 3 b, 5 a, 5 b, 6 a, 6 c, 6 d, 7 b, 7 c$ \\
\hline Station S43 & -74.2655 & 132.9633 & -4752 & Em/Isip & Boulder (N/A) & $2 b, 2 d, 3 a, 3 b, 6 a, 6 c, 6 d$ \\
\hline Station 544 & -74.3108 & 132.8374 & -4736 & Isip & Boulder (N/A) & $6 a, 6 c, 6 d$ \\
\hline Station S45 & -74.4394 & 132.9465 & -4673 & Isip & Mixed rake (333) & $1 a, 1 c, 1 e, 3 d, 6 a, 6 c, 6 d$ \\
\hline Station 546 & -74.4998 & 133.4288 & -4703 & Isip & Mixed rake (333) & $1 a, 1 c, 1 e, 3 d, 6 a, 6 c, 6 d$ \\
\hline Station S47 & -74.6019 & 133.3457 & -4676 & Isip & Mixed rake (333) & $1 a, 1 c, 1 e, 3 d, 6 a, 6 c, 6 d$ \\
\hline Station 548 & -74.8181 & 133.4272 & -4642 & Isip & Boulder $(5000)^{b}$ & $1 a, 1 c, 1 e, 6 a, 6 c, 6 d$ \\
\hline Station 549 & -74.9557 & 133.0139 & -4481 & Isip & Regolith (2000) & $1 a, 1 c, 2 a, 2 b, 2 d, 3 a, 3 b, 3 c, 3 d, 5 a, 5 b, 5 d, 6 a, 7 b, 7 c$ \\
\hline Station S50 & -75.0866 & 133.3906 & -4595 & Isip & Regolith (N/A) & $2 a, 2 b, 2 d, 3 a, 3 b, 3 c, 3 d, 5 a, 5 b, 6 a, 7 b, 7 c$ \\
\hline Landing site 3 & -75.1710 & 133.3401 & -4587 & & $\begin{array}{l}\text { (Total: } 9.0 \mathrm{~kg} \text { ) } \\
\text { (Traverse total: } 28.5 \mathrm{~kg} \text { ) }\end{array}$ & \\
\hline
\end{tabular}

a Based on M3 spectra considered to be a crystalline, homogeneous rock (sample mass after Shearer et al., 2007)

${ }^{\mathrm{b}}$ Assumed to be heterogeneous impact melt breccia (sample mass after CAPTEM, 2007)

${ }^{1}$ Kramer et al. (2013) ${ }^{2}$ Based on CAPTEM recommendations (Shearer et al., 2007) ${ }^{3}$ NRC (2007) 
Table S.2. Summary of location, type of sample and mass, type of in-situ analyses and scientific goals (NRC, 2007) that can be addressed at the identified stations of the long traverse assuming a notional baseline of $<30 \mathrm{~kg}$ of total returned sample mass

\begin{tabular}{|c|c|c|c|c|c|c|}
\hline & Latitude & Longitude & Elevation (m) & $\begin{array}{l}\text { Lithological } \\
\text { unit }^{1}\end{array}$ & $\begin{array}{l}\text { Sample type } \\
\text { and mass }(g)^{2}\end{array}$ & Scientific goals addressed $^{3}$ \\
\hline Landing site 1 & -75.4050 & 141.1768 & -4733 & & & \\
\hline Station S1 & -75.4907 & 141.3745 & -4723 & Ep & Regolith (2000) & $2 b, 2 d, 5 c, 5 d, 7 b, 7 c$ \\
\hline Station S2 & -75.4906 & 142.0473 & -4541 & $\mathrm{pNpr}$ & Boulder $(500)^{\mathrm{a}}$ & $2 a, 3 a, 3 b, 3 c, 3 d$ \\
\hline Station S3 & -75.3983 & 142.1327 & -4520 & $\mathrm{pNpr}$ & Boulder $(500)^{\mathrm{a}}$ & $2 a, 3 a, 3 b, 3 c, 3 d$ \\
\hline Station 54 & -75.3651 & 142.1738 & -4465 & $\mathrm{pNpr}$ & Boulder (N/A) & $2 a, 3 a, 3 b, 3 c, 3 d$ \\
\hline Station S5 & -75.2628 & 142.2408 & -4506 & $\mathrm{pNpr}$ & Boulder $(500)^{a}$ & $2 a, 3 a, 3 b, 3 c, 3 d$ \\
\hline Station S6 & -75.1507 & 141.9541 & -4820 & $\mathrm{Ep} / \mathrm{pNpr}$ & Mixed rake (1000) & $2 a, 2 b, 2 d, 3 a, 3 b, 3 c, 3 d,(4 a, 4 b, 4 c), 5 c, 5 d$ \\
\hline Station S7 & -75.2560 & 141.8327 & -4651 & lipr & Boulder (N/A) & $6 c$ \\
\hline Station S8 & -75.3027 & 141.9196 & -4618 & lipr & Boulder $(5000)^{b}$ & $1 \mathrm{a}, 1 \mathrm{c}, 1 \mathrm{~d}, 6 \mathrm{c}$ \\
\hline Station S9 & -75.4149 & 141.4296 & -4740 & Ep & Regolith (N/A) & $2 b, 2 d, 5 c, 5 d, 7 b, 7 c$ \\
\hline Landing site 1 & -75.4050 & 141.1768 & -4733 & & (Total: 9.5 kg) & \\
\hline Station S10 & -75.3602 & 140.9211 & -4706 & Ep & Boulder (N/A) & $2 b, 2 d, 5 c, 5 d, 6 c, 6 d$ \\
\hline Station S11 & -75.3370 & 140.8480 & -4734 & Ep & Regolith (N/A) & $2 b, 2 d, 5 c, 5 d, 6 c, 6 d, 7 b, 7 c$ \\
\hline Station $S 12$ & -75.3121 & 140.4326 & -4590 & Ep & Boulder (N/A) & $2 b, 2 d, 5 c, 5 d, 6 c$ \\
\hline Station $\mathrm{S13}$ & -75.2946 & 140.3430 & -4586 & Ep & Regolith (N/A) & $2 b, 2 d, 3 b, 5 c, 5 d, 7 b, 7 c$ \\
\hline Station S14 & -75.2554 & 140.2323 & -4572 & Ep & Regolith (2000) & $1 d, 2 b, 2 d, 5 c, 5 d, 7 b, 7 c$ \\
\hline Station L1 & -75.3675 & 138.5676 & -4336 & Ep & Regolith (N/A) & $2 b, 2 d, 5 c, 5 d, 7 b, 7 c$ \\
\hline Station L2 & -75.6870 & 138.6578 & -4745 & Ep & Boulder (N/A) & $2 b, 2 d, 5 c, 5 d, 6 c$ \\
\hline Station L3 & -75.7592 & 138.7186 & -4735 & Isc & Mixed Rake (N/A) & $2 b, 2 d, 5 c, 5 d, 6 a, 6 c, 6 d$ \\
\hline Station L4 & -75.7703 & 138.4000 & -4738 & Isc & Mixed Rake (N/A) & $2 b, 2 d, 5 c, 5 d, 6 a, 6 c, 6 d$ \\
\hline Station 15 & -75.8157 & 138.2629 & -4668 & Isc & Mixed Rake (N/A) & $2 b, 2 d, 5 c, 5 d, 6 a, 6 c, 6 d$ \\
\hline Station L6 & -75.8212 & 138.0631 & -4712 & Isip & Boulder (N/A) & $6 a, 6 c, 6 d$ \\
\hline Station $L 7$ & -76.0064 & 137.7253 & -4737 & Isip & Regolith (N/A) & $6 a, 6 c, 6 d, 7 b, 7 c$ \\
\hline Station L8 & -76.1349 & 137.8276 & -4698 & Isip & Regolith (N/A) & $6 a, 6 c, 6 d, 7 b, 7 c$ \\
\hline Station 19 & -76.0830 & 138.2716 & -4692 & Isc & Boulder (N/A) & $6 a, 6 c, 6 d$ \\
\hline Station L10 & -76.1640 & 138.8389 & -4706 & Isc & Regolith (N/A) & $6 a, 6 c, 6 d, 7 b, 7 c$ \\
\hline Station L11 & -76.3181 & 138.6777 & -4637 & Isc & Boulder (N/A) & $6 a, 6 c, 6 d$ \\
\hline Station L12A & -76.5039 & 138.4047 & -4597 & Isc & Boulder $(5000)^{b}$ & $1 \mathrm{a}, 1 \mathrm{c}, 1 \mathrm{~d}, 1 \mathrm{e}, 6 \mathrm{a}, 6 \mathrm{c}, 6 \mathrm{~d}$ \\
\hline Station L12B & -76.5969 & 139.9789 & -4550 & Isc & Boulder (N/A) & $6 \mathrm{a}, 6 \mathrm{c}, 6 \mathrm{~d}$ \\
\hline Station L13 & -76.7729 & 141.1660 & -4622 & Isop & Boulder (N/A) & $6 a, 6 c, 6 d$ \\
\hline Station L14 & -76.7558 & 141.3614 & -4642 & Isop/Isc & Boulder (N/A) & $6 a, 6 c, 6 d$ \\
\hline Station L15 & -76.8070 & 141.8635 & -4683 & Isop & Boulder (N/A) & $6 a, 6 c, 6 d$ \\
\hline Station L16 & -76.6487 & 142.9195 & -4429 & Iw slump & Boulder $(500)^{*}$ & $2 a, 3 a, 3 b, 3 c, 3 d$ \\
\hline Station L17 & -76.8625 & 142.7509 & -4722 & Iw slump & Boulder (N/A) & $2 a, 3 a, 3 b, 3 c, 3 d$ \\
\hline Station L18 & -76.8940 & 142.7962 & -4661 & Iw slump & Boulder (N/A) & $2 a, 3 a, 3 b, 3 c, 3 d$ \\
\hline Station L19 & -76.9163 & 142.7086 & -4714 & Iw slump & Boulder $(500)^{a}$ & $2 a, 3 a, 3 b, 3 c, 3 d$ \\
\hline Station L20 & -76.9627 & 142.5892 & -4716 & Isop/Iw slump & Boulder (N/A) & $2 a, 3 a, 3 b, 3 c, 3 d$ \\
\hline Station L21 & -77.0552 & 142.6220 & -4686 & Isop & Boulder (N/A) & $6 a, 6 c, 6 d$ \\
\hline Station L22 & -77.1993 & 142.6219 & -4688 & Isop & Regolith/Boulder (N/A) & $6 a, 6 c, 6 d,(7 b, 7 c)$ \\
\hline Station L23 & -77.2073 & 142.5837 & -4685 & Isc/Isop & Boulder (N/A) & $6 a, 6 c, 6 d$ \\
\hline Station L24 & -77.3054 & 142.8158 & -4680 & Isc & Boulder (N/A) & $6 a, 6 c, 6 d$ \\
\hline Station L25 & -77.3787 & 142.5967 & -4615 & Isc & Regolith (2000) & $1 a, 1 b, 1 c, 1 e, 6 a, 6 c, 6 d, 7 b, 7 c$ \\
\hline Station L26 & -77.4581 & 142.0336 & -4599 & Isc/Isop & Boulder (N/A) & $6 a, 6 c, 6 d$ \\
\hline Landing site 2 & -77.4732 & 141.8233 & -4597 & & (Total: $10.0 \mathrm{~kg}$ ) & \\
\hline Station $L 27$ & -77.5210 & 142.1097 & -4630 & Isop & Boulder (N/A) & $6 a, 6 c, 6 d$ \\
\hline Station L28 & -77.6336 & 142.0954 & -4622 & Isop & Boulder (N/A) & $6 a, 6 c, 6 d$ \\
\hline Station L29 & -77.6596 & 142.0155 & -4609 & Isop/Isc & Boulder (N/A) & $6 a, 6 c, 6 d$ \\
\hline Station L30 & -77.7209 & 142.4214 & -4628 & Isop & Mixed Rake (1000) & $1 a, 1 b, 1 c, 1 e, 6 a, 6 c, 6 d$ \\
\hline Station L31 & -77.8093 & 142.1883 & -4605 & Isop/Isc & Boulder (N/A) & $6 a, 6 c, 6 d$ \\
\hline Station L32 & -77.8770 & 142.2026 & -4609 & Isc/Isop & Boulder (N/A) & $6 a, 6 c, 6 d$ \\
\hline Station L33 & -78.0937 & 142.0777 & -4608 & Ish & Boulder (N/A) & $6 a, 6 c, 6 d$ \\
\hline Station L34 & -78.0927 & 142.0508 & -4609 & Ish & Boulder (N/A) & $6 a, 6 c, 6 d$ \\
\hline Station L35 & -78.0954 & 142.0484 & -4607 & Ish & Regolith (N/A) & $7 b, 7 c$ \\
\hline Station L36 & -78.1133 & 141.6494 & -4571 & Ish & Boulder (N/A) & $6 a, 6 c, 6 d$ \\
\hline Station $L 37$ & -78.3246 & 142.5125 & -4617 & Isc & Boulder (N/A) & $6 a, 6 c, 6 d$ \\
\hline Station L38 & -78.4942 & 142.3218 & -4615 & $\mathrm{Ish} / \mathrm{Iw} / \mathrm{Isc}$ & Boulder (N/A) & $2 a, 3 a, 3 b, 3 c, 3 d, 6 a, 6 c, 6 d$ \\
\hline Station L39 & -78.5627 & 141.5129 & -4521 & $\mathrm{Iw} / \mathrm{Ish}$ & Boulder (N/A) & $2 a, 3 a, 3 b, 3 c, 3 d, 6 a, 6 c, 6 d$ \\
\hline Station L4O & -78.5974 & 141.1479 & -4489 & $\mathrm{Iw} / \mathrm{Ish}$ & Boulder (N/A) & $2 a, 3 a, 3 b, 3 c, 3 d, 6 a, 6 c, 6 d$ \\
\hline Station L41 & -78.6726 & 141.0683 & -4375 & $\mathrm{Iw} / \mathrm{Ish}$ & Boulder (N/A) & $2 a, 3 a, 3 b, 3 c, 3 d, 6 a, 6 c, 6 d$ \\
\hline
\end{tabular}




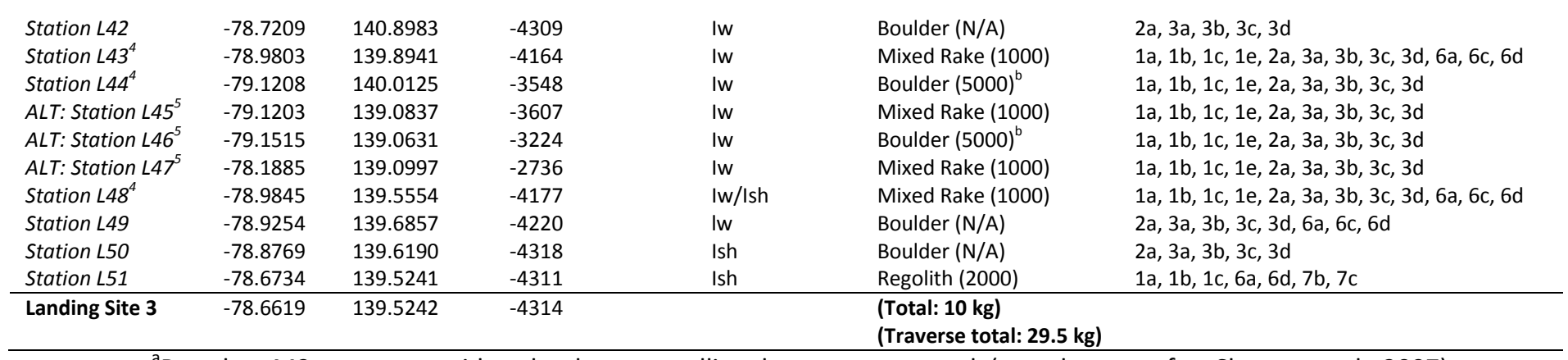

${ }^{a}$ Based on M3 spectra considered to be a crystalline, homogeneous rock (sample mass after Shearer et al., 2007)

${ }^{b}$ Assumed to be heterogeneous impact melt breccia (sample mass after CAPTEM, 2007)

${ }^{1}$ Kramer et al. (2013) ${ }^{2}$ Based on CAPTEM recommendations (Shearer et al., 2007) ${ }^{3} \mathrm{NRC}(2007){ }^{4}$ Proposed sites from this study to sample SPA material ${ }^{5}$ Alternative sites for sampling SPA material based on Hurwitz and Kring (2015)

Table S.3. The collected lithologies and their relative abundances during each section of the short and long traverse based on CAPTEM recommendations (Shearer et al., 2007).

\begin{tabular}{lllll}
\hline & Basalt & Impact breccia & Regolith & Homogeneous $^{\text {a }}$ \\
\hline Short traverse & & & & \\
Section 1 & 0.0 & 0.6 & 0.2 & 0.2 \\
Section 2 & 0.1 & 0.5 & 0.4 & 0.0 \\
Section 3 & 0.1 & 0.7 & 0.2 & 0.0 \\
Long traverse & & & & 0.2 \\
Section 1 & 0.0 & 0.6 & 0.2 & 0.1 \\
Section 2 & 0.0 & 0.7 & 0.2 & 0.0 \\
Section 3 & 0.0 & 0.8 & 0.2 & \\
\hline
\end{tabular}

${ }^{\mathrm{a}}$ Homogeneous rocks include anorthosites, norites and dunites.

Table S.4. Properties of each engine type.

\begin{tabular}{lllll}
\hline & Aestus & Aestus II & AJ-10 & R-40B \\
\hline Propellant type & MMH & MMH & Aerozine 50 & MMH \\
Oxidizer & NTO & NTO & NTO & NTO \\
Propellant boiling point (F) & 190 & 190 & 158 & 190 \\
Propellant freezing point (F) & -62.3 & -62.3 & 19.4 & -62.3 \\
ISP (s) & 324 & 340 & 319 & 293 \\
Thrust (N) & 29600 & 55400 & 43700 & 4000 \\
Dry mass (kg) & $111 \mathrm{~kg}$ & $138 \mathrm{~kg}$ & $100 \mathrm{~kg}$ & $6.8 \mathrm{~kg}$ \\
\hline
\end{tabular}

Table S.5. Boulder locations and properties that were used to assess the bearing capacity of the pyroclastic material.

\begin{tabular}{lllllllll}
\hline Boulder & Latitude & Longitude & $\begin{array}{l}\text { Boulder } \\
\text { Radius }(\mathbf{c m})\end{array}$ & $\begin{array}{l}\text { Radius at } \\
\text { Surface }(\mathbf{c m})\end{array}$ & $\begin{array}{l}\text { Track Width } \\
(\mathbf{m})\end{array}$ & $\begin{array}{l}\text { Track } \\
\text { Length }(\mathbf{m})\end{array}$ & Slope $\left(^{\circ}\right)$ & $\begin{array}{l}\text { Track Depth } \\
(\mathbf{c m})\end{array}$ \\
\hline $\mathbf{1}$ & -75.156 & 140.118 & 297.5 & 275 & 4.14 & 120 & $2-4$ & 183 \\
$\mathbf{2}$ & -75.163 & 140.131 & 259 & 251 & 3.68 & 98 & $2-4$ & 195 \\
$\mathbf{3}$ & -75.309 & 139.173 & 544.5 & 521 & 6.5 & 356 & $10-12$ & 387 \\
\hline
\end{tabular}


Table S.6. Calculations of the bearing capacity $\left(\right.$ dynes $/ \mathrm{cm}^{2}$ ) of the pyroclastic material for an assumed internal friction angle of $30^{\circ}$.

\begin{tabular}{|c|c|c|c|c|}
\hline \multirow[b]{2}{*}{ Boulder } & \multicolumn{2}{|c|}{ Soil Density $=2 \mathrm{~g} / \mathrm{cm}^{2}$} & \multicolumn{2}{|c|}{ Soil Density $=2.29 \mathrm{~g} / \mathrm{cm}^{2}$} \\
\hline & $\begin{array}{l}\text { Bearing Capacity } \\
\left.\text { (dynes } / \mathrm{cm}^{2}\right)\end{array}$ & $\begin{array}{l}\text { Bearing Capacity } \\
\left(\mathrm{kN} / \mathrm{m}^{2}\right)\end{array}$ & $\begin{array}{l}\text { Bearing Capacity } \\
\left.\text { (dynes/cm } / \mathrm{cm}^{2}\right)\end{array}$ & $\begin{array}{l}\text { Bearing Capacity } \\
\left(\mathrm{kN} / \mathrm{m}^{2}\right)\end{array}$ \\
\hline 1 & $2.60 \times 10^{6}$ & $2.57 \times 10^{5}$ & $2.80 \times 10^{6}$ & $2.80 \times 10^{5}$ \\
\hline 2 & $2.59 \times 10^{6}$ & $2.59 \times 10^{5}$ & $2.81 \times 10^{6}$ & $2.81 \times 10^{5}$ \\
\hline 3 & $5.19 \times 10^{6}$ & $5.19 \times 10^{5}$ & $5.62 \times 10^{6}$ & $5.62 \times 10^{5}$ \\
\hline Average & $3.46 \times 10^{6}$ & $3.45 \times 10^{5}$ & $3.74 \times 10^{6}$ & $3.74 \times 10^{5}$ \\
\hline
\end{tabular}

Table S.7. Calculations of the bearing capacity $\left(\right.$ dynes $/ \mathrm{cm}^{2}$ ) of the pyroclastic material for an assumed internal friction angle of $35^{\circ}$.

\begin{tabular}{|c|c|c|c|c|}
\hline \multirow[b]{2}{*}{ Boulder } & \multicolumn{2}{|c|}{ Soil Density $=2 \mathrm{~g} / \mathrm{cm}^{2}$} & \multicolumn{2}{|c|}{ Soil Density $=2.29 \mathrm{~g} / \mathrm{cm}^{2}$} \\
\hline & $\begin{array}{l}\text { Bearing Capacity } \\
\text { (dynes } / \mathrm{cm}^{2} \text { ) }\end{array}$ & $\begin{array}{l}\text { Bearing Capacity } \\
\left(\mathrm{kN} / \mathrm{m}^{2}\right)\end{array}$ & $\begin{array}{l}\text { Bearing Capacity } \\
\left.\text { (dynes } / \mathrm{cm}^{2}\right)\end{array}$ & $\begin{array}{l}\text { Bearing Capacity } \\
\left(\mathrm{kN} / \mathrm{m}^{2}\right)\end{array}$ \\
\hline 1 & $4.82 \times 10^{6}$ & $4.82 \times 10^{5}$ & $5.18 \times 10^{6}$ & $5.18 \times 10^{5}$ \\
\hline 2 & $4.79 \times 10^{6}$ & $4.79 \times 10^{5}$ & $5.17 \times 10^{6}$ & $5.17 \times 10^{5}$ \\
\hline 3 & $9.62 \times 10^{6}$ & $9.62 \times 10^{5}$ & $1.04 \times 10^{7}$ & $1.04 \times 10^{6}$ \\
\hline Average & $6.41 \times 10^{6}$ & $6.41 \times 10^{5}$ & $6.91 \times 10^{6}$ & $6.91 \times 10^{2}$ \\
\hline
\end{tabular}

Table S.8. Summary of trade study between KA-band and laser communication.

\begin{tabular}{lll}
\hline & KA-band & Laser \\
\hline Data rate & $5-100 \mathrm{Mbps}$ & Up to $600 \mathrm{Mbps}$ \\
$\begin{array}{l}\text { Bandwidth } \\
\text { Power }\end{array}$ & $32 \mathrm{GHz}$ & $300,000 \mathrm{GHz}$ \\
Heritage & & Half of KA-band \\
Earth weather impact & $>15$ missions & LLCD \\
No. of ground stations required & No & Yes \\
Forward application for Mars & Currently >4, sufficient & Additional needed \\
Download time for "Apollo 13" movie (36.000 MB) & No, currently in use & Yes \\
\hline
\end{tabular}


Fig. S.1. The mass capability for different sample container internal diameters assuming the lithology sample proportions from Table S.1. The minimum and maximum mass capabilities were calculated using the upper and lower bound of the estimated densities of each lithology (see text).

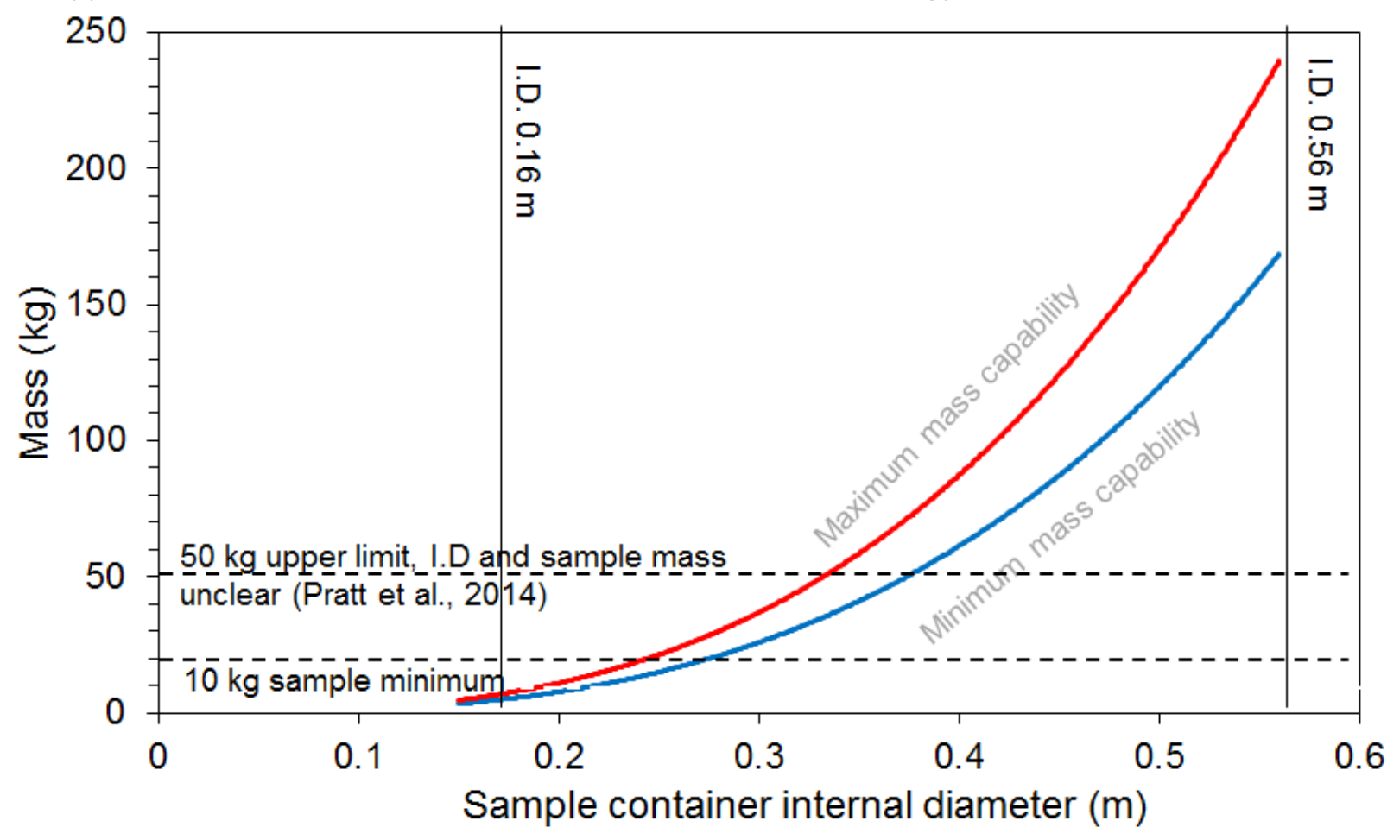

Fig. S.2. The maximum payload $(\mathrm{kg})$ as a function of the ascent vehicle tanksize volume $\left(\mathrm{m}^{3}\right)$.

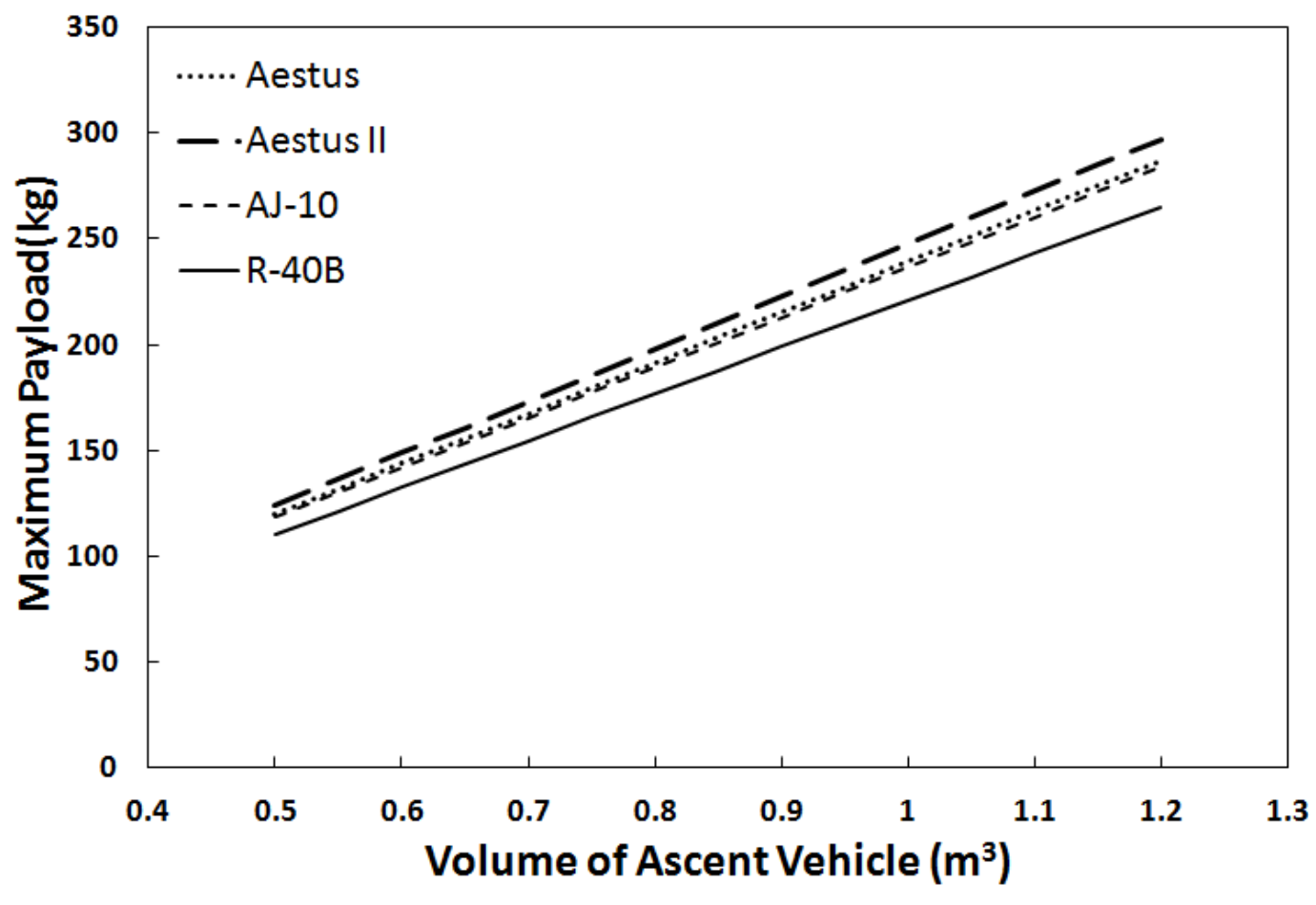


Fig. S.3. Dimensions of the ascent vehicle as a function of payload size (sample mass) assuming an Aestus II engine with Monomethylhydrazine ( $\mathrm{MMH}$ ) propellant. The left-most vehicle represents the size of the vehicle required for the $11 \mathrm{~kg}$ payload, and the others explore what would be required to deliver larger payloads from the lunar surface to the eDSH $(20,50$ and $100 \mathrm{~kg}$, respectively).

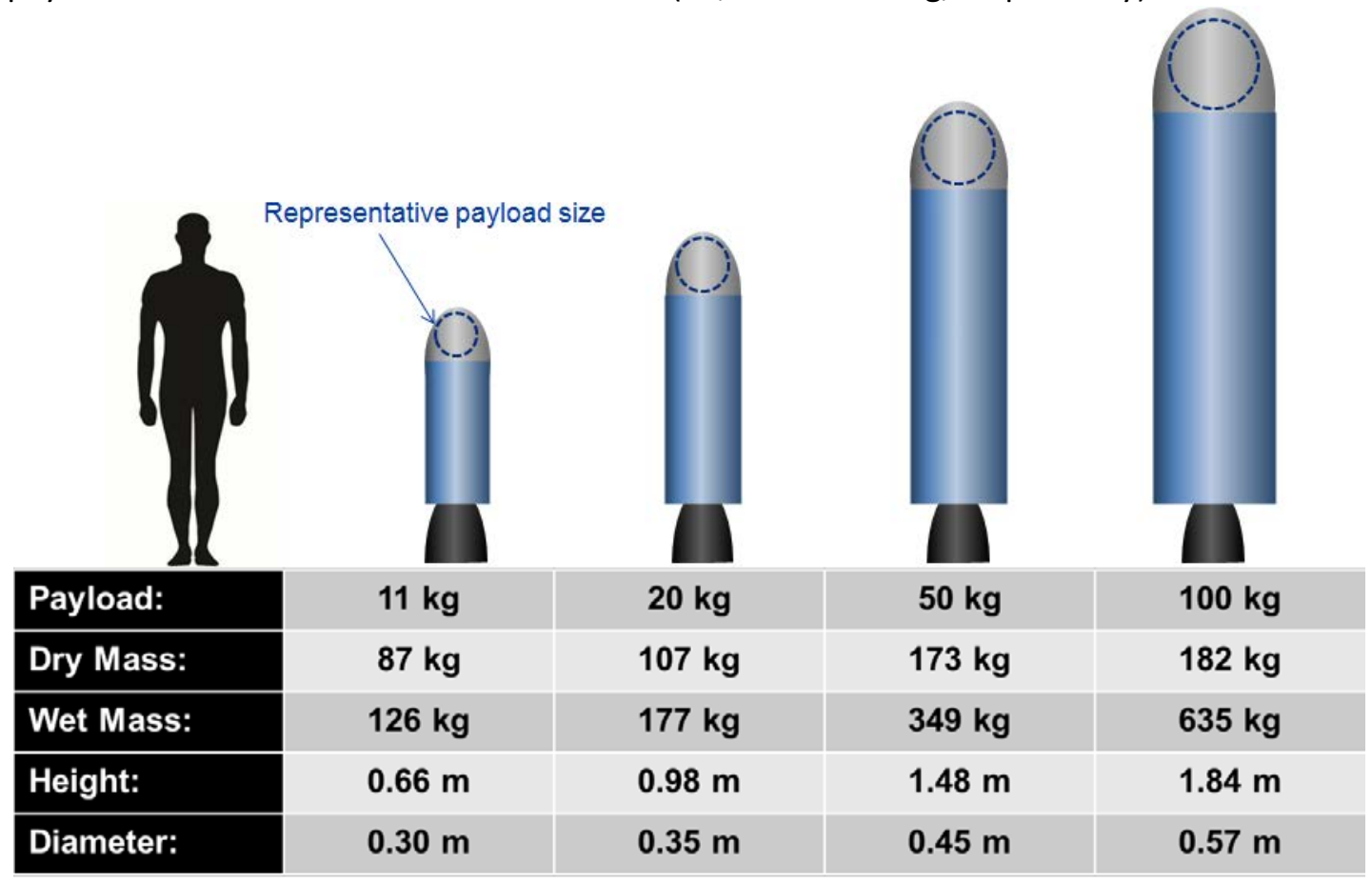

Fig. S.4. Qualitative assessment of crater degradation state of craters along the short and long traverse (modified from Wilhelms, 1984)

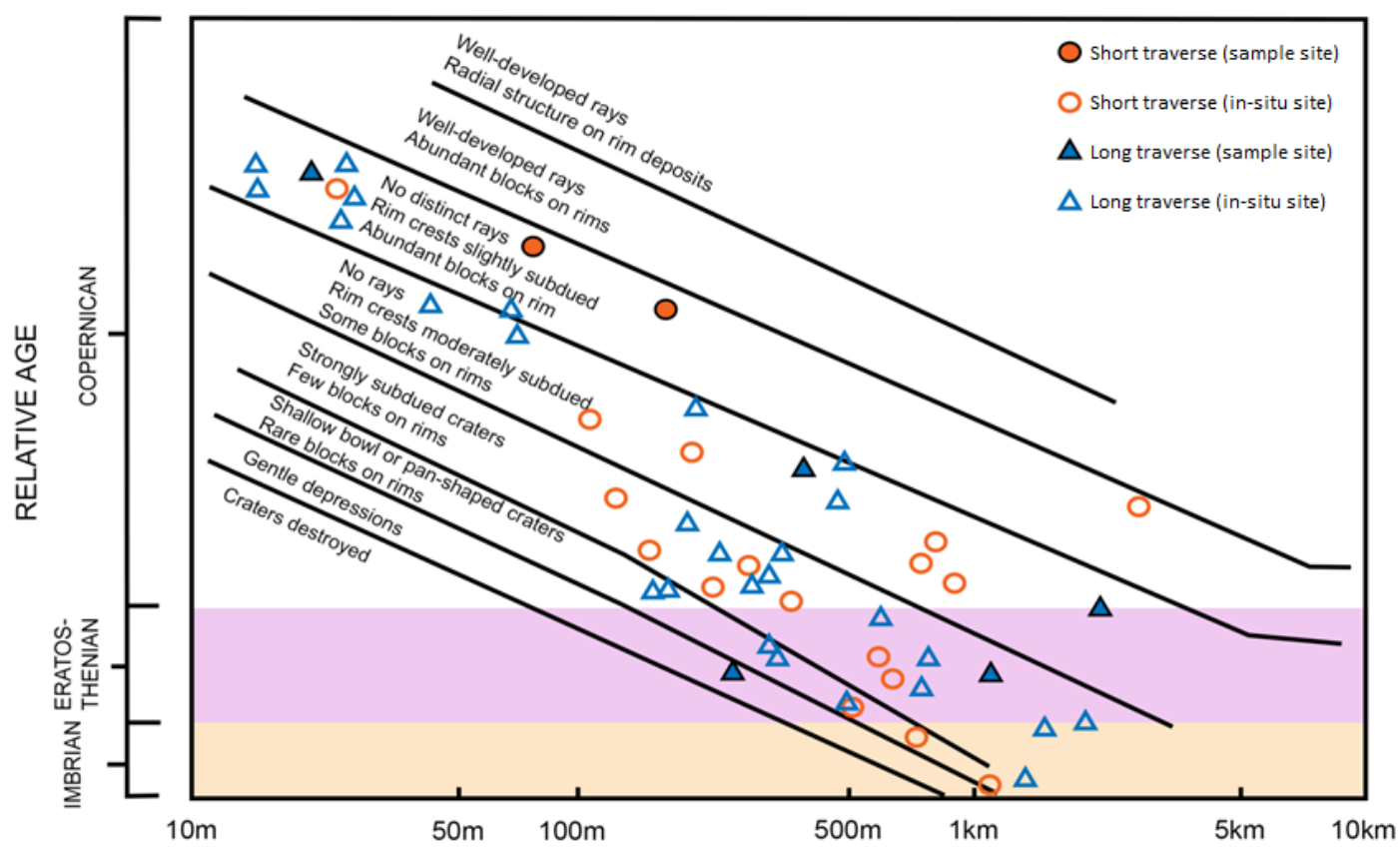




\section{Figure 1A-B}

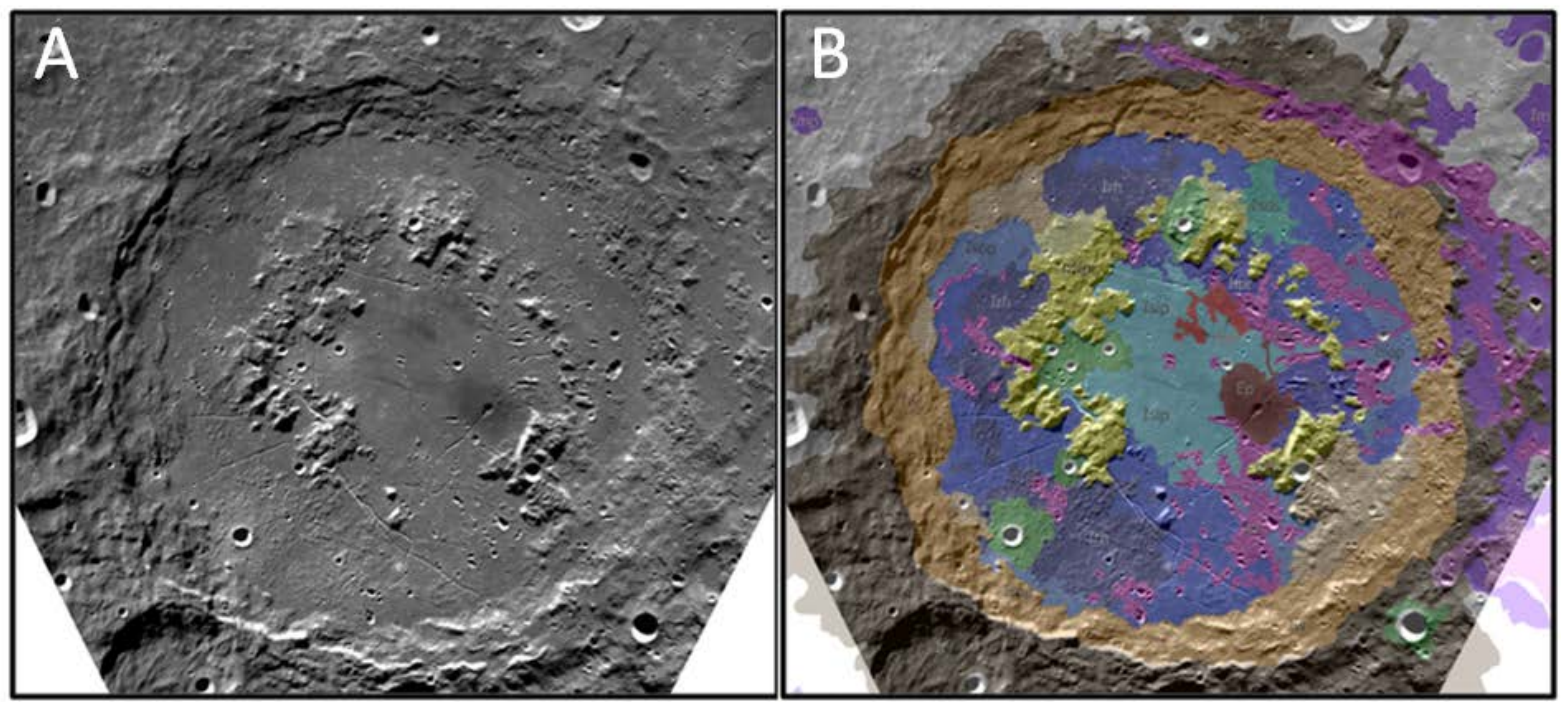

Figure 2

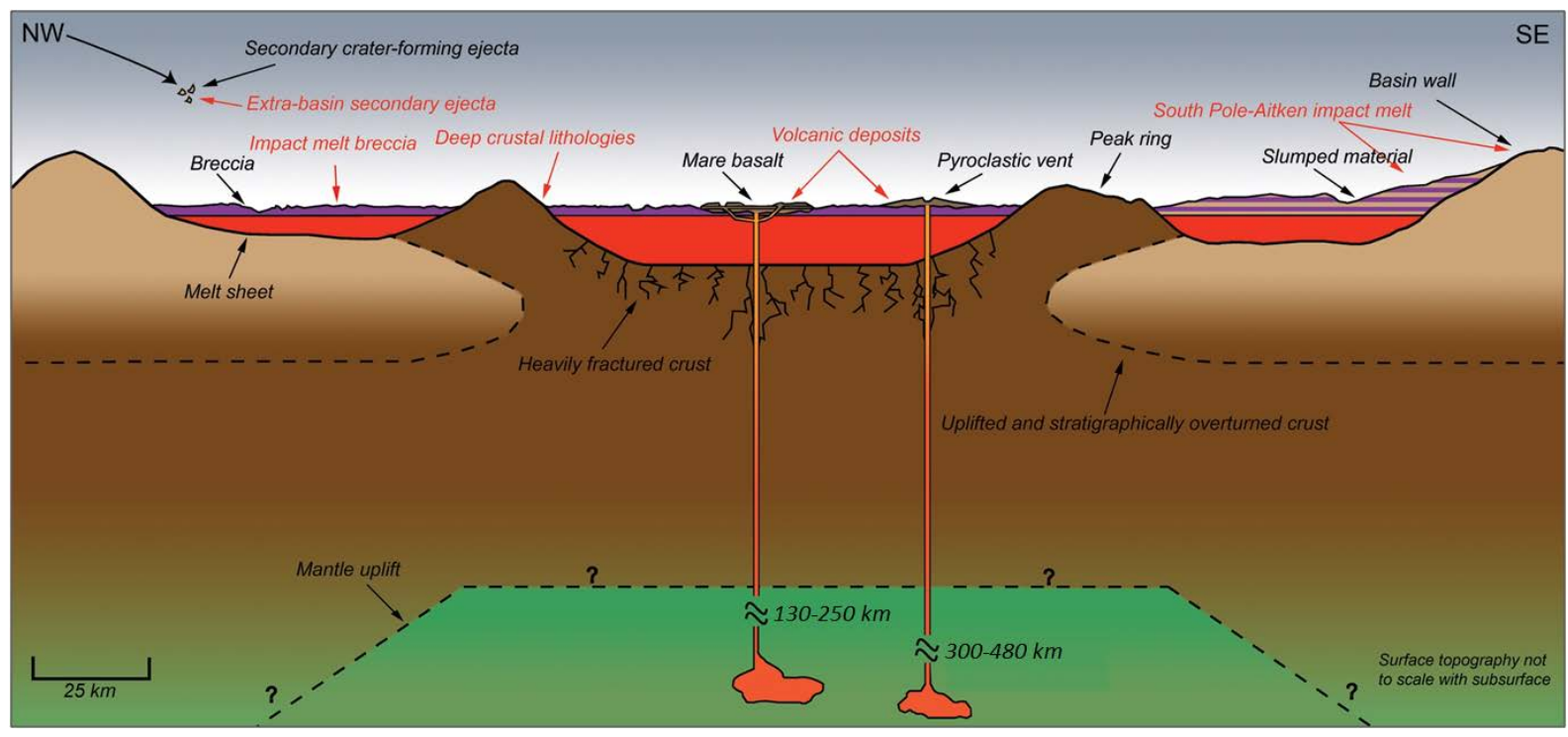

\section{Figure 3}

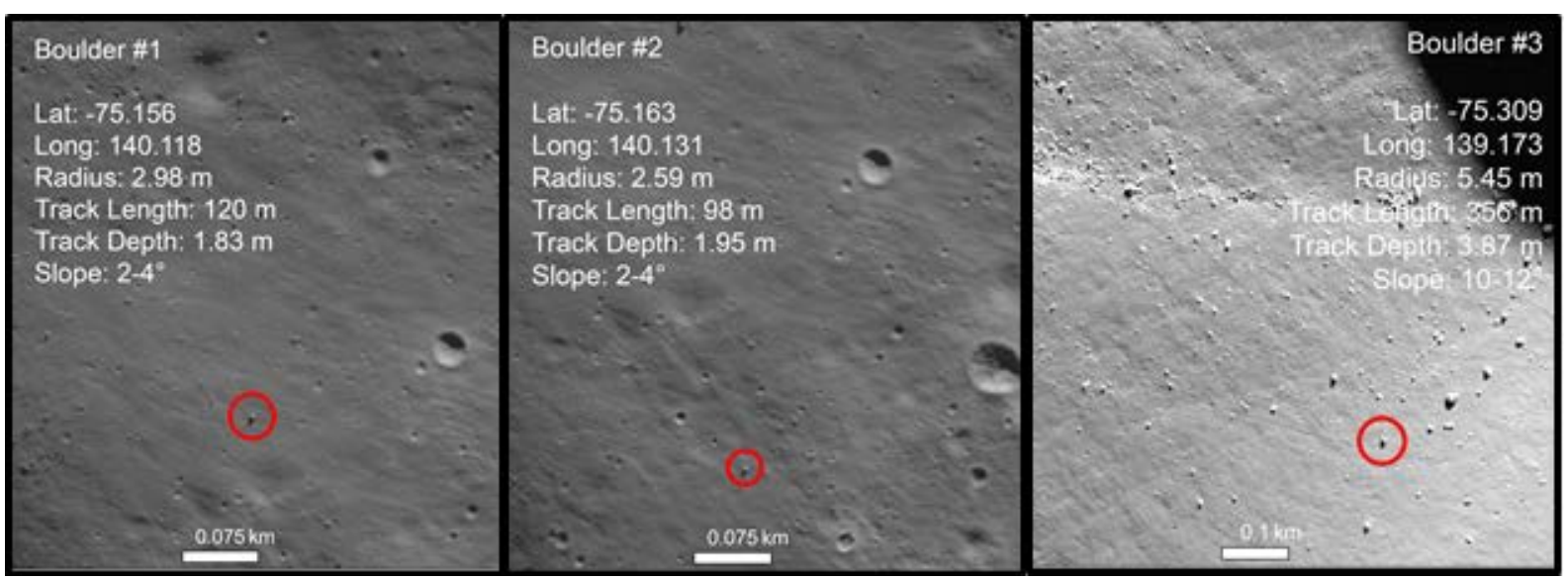


Figure 4A-B

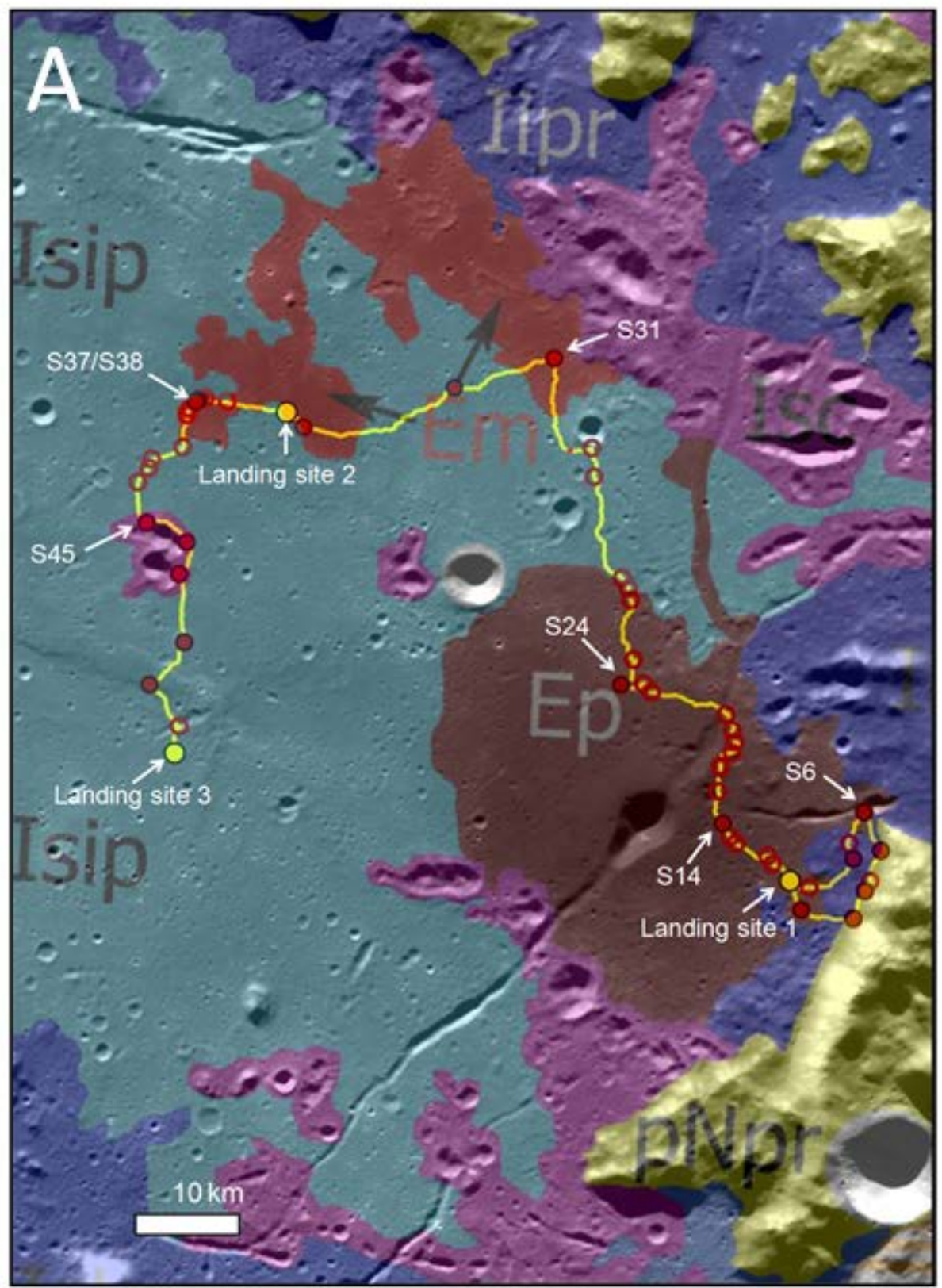



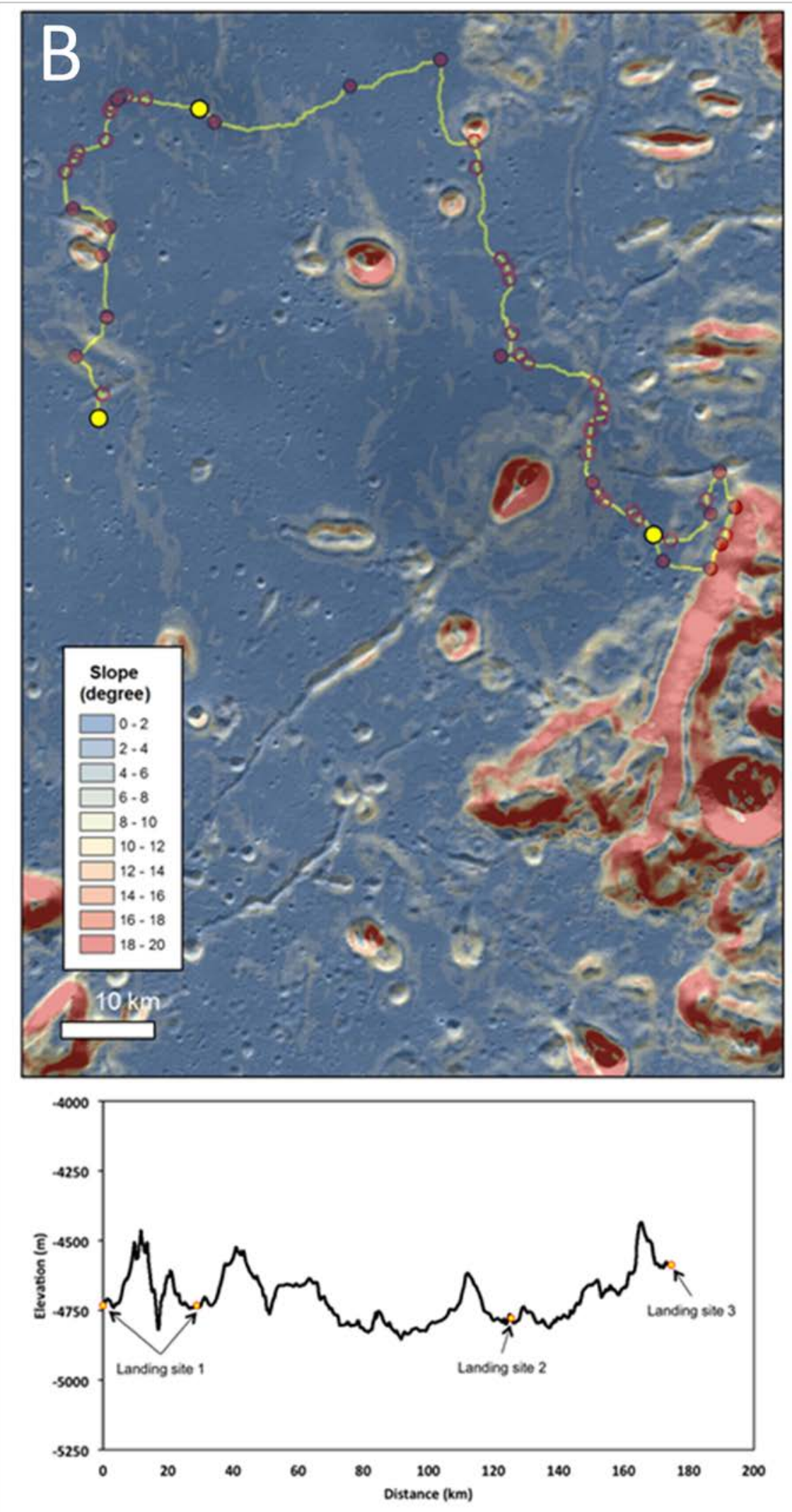
Figure 5A-E
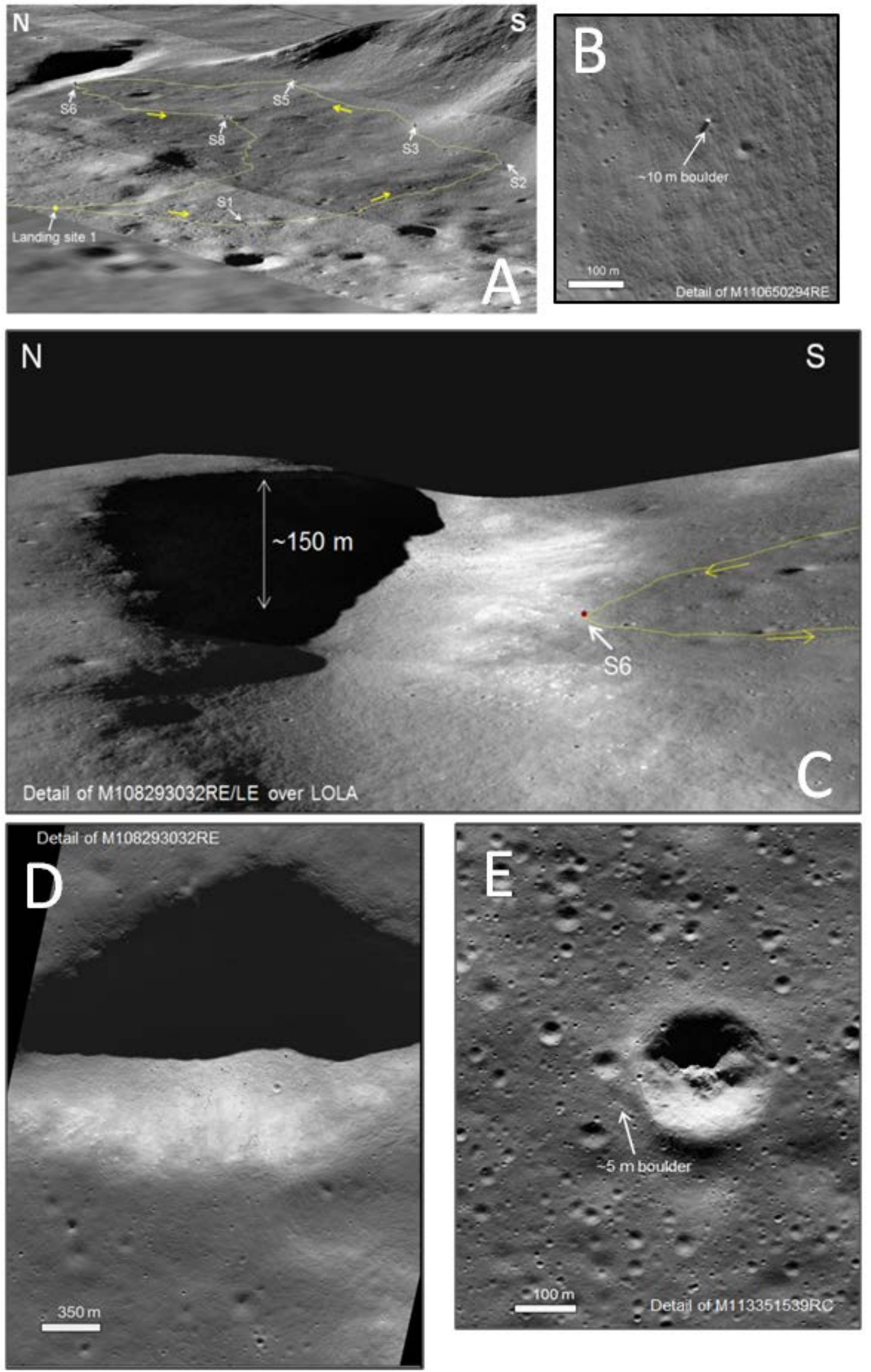
Figure 6

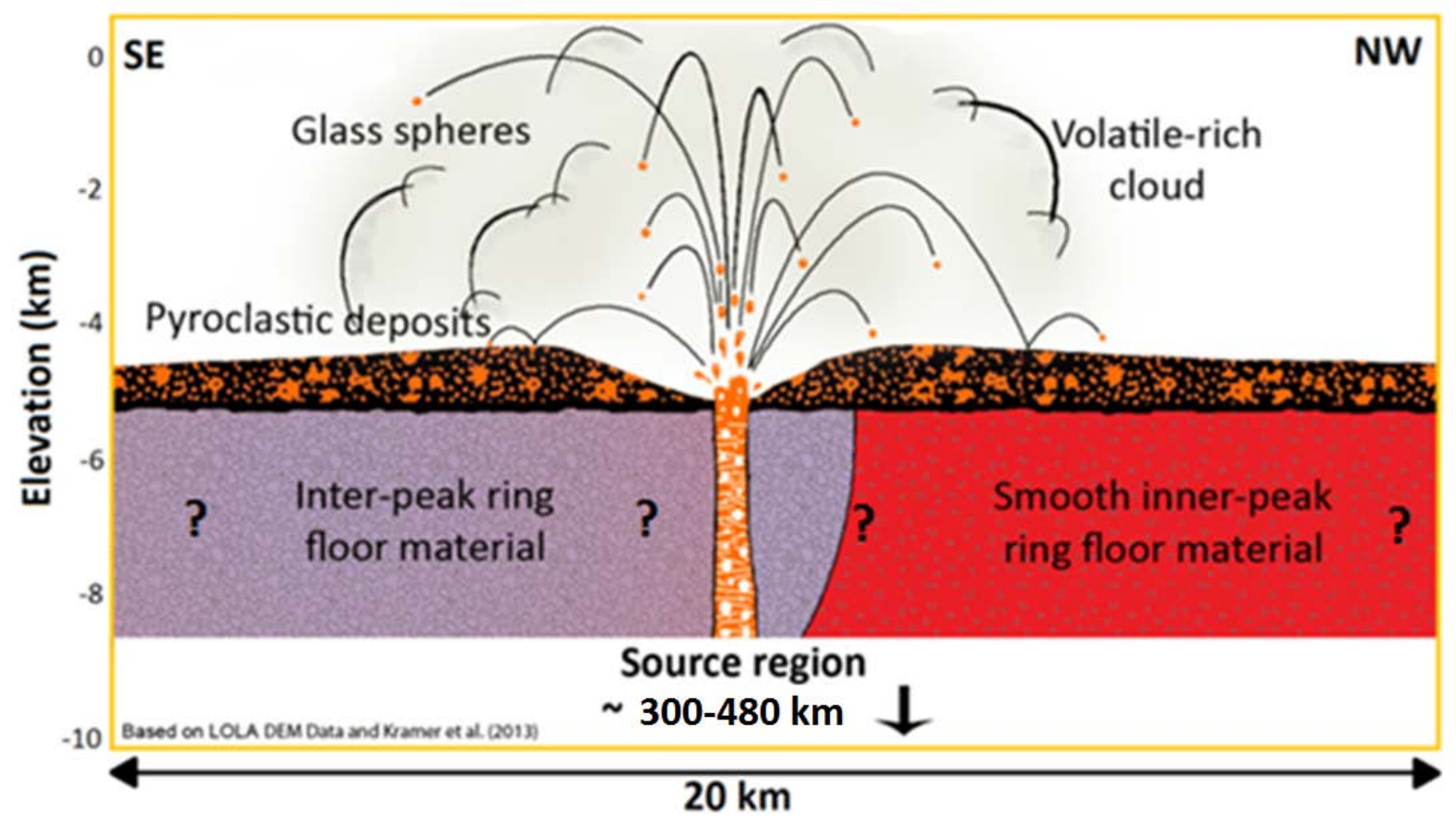

Figure 7

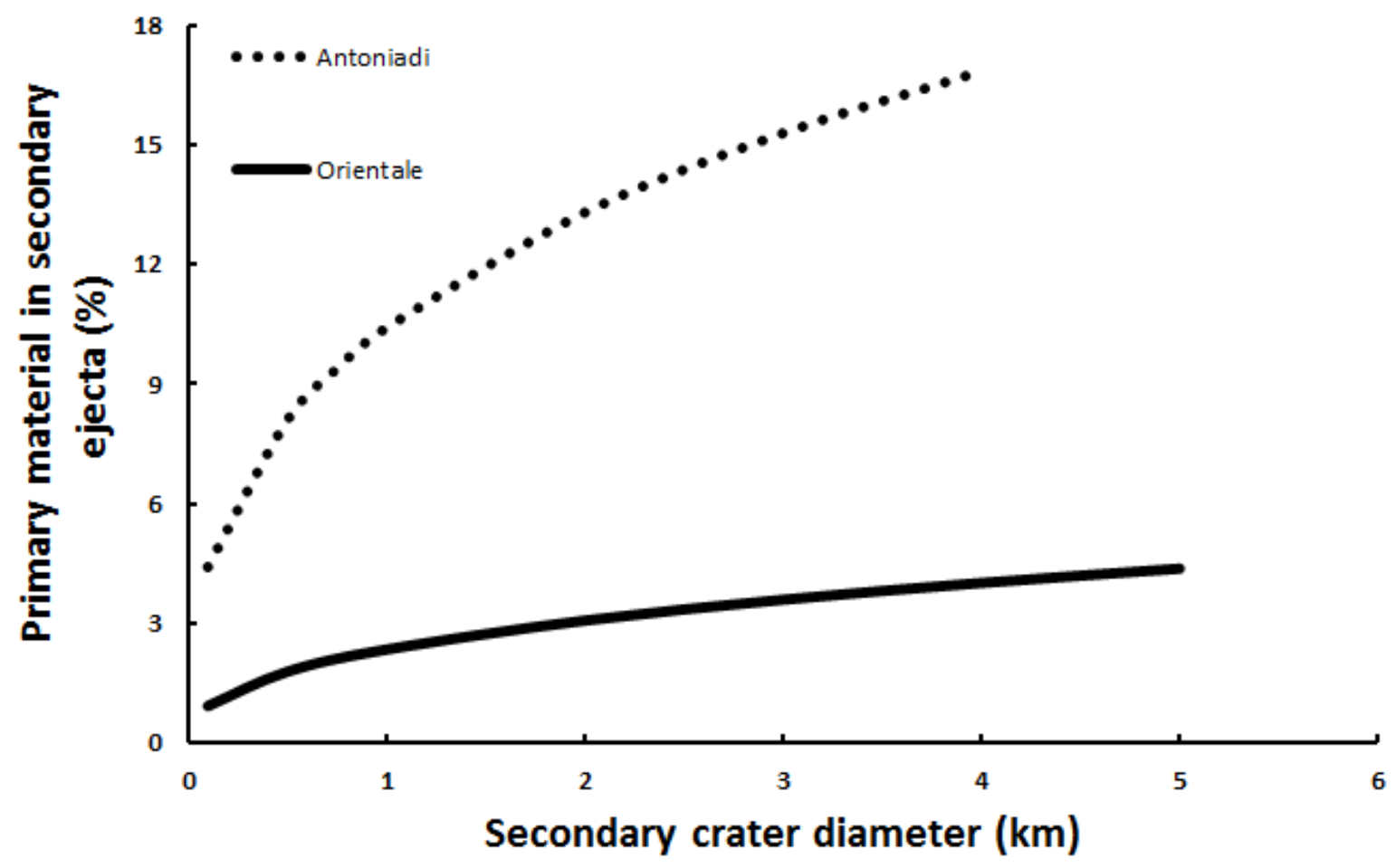


Figure 8A-B

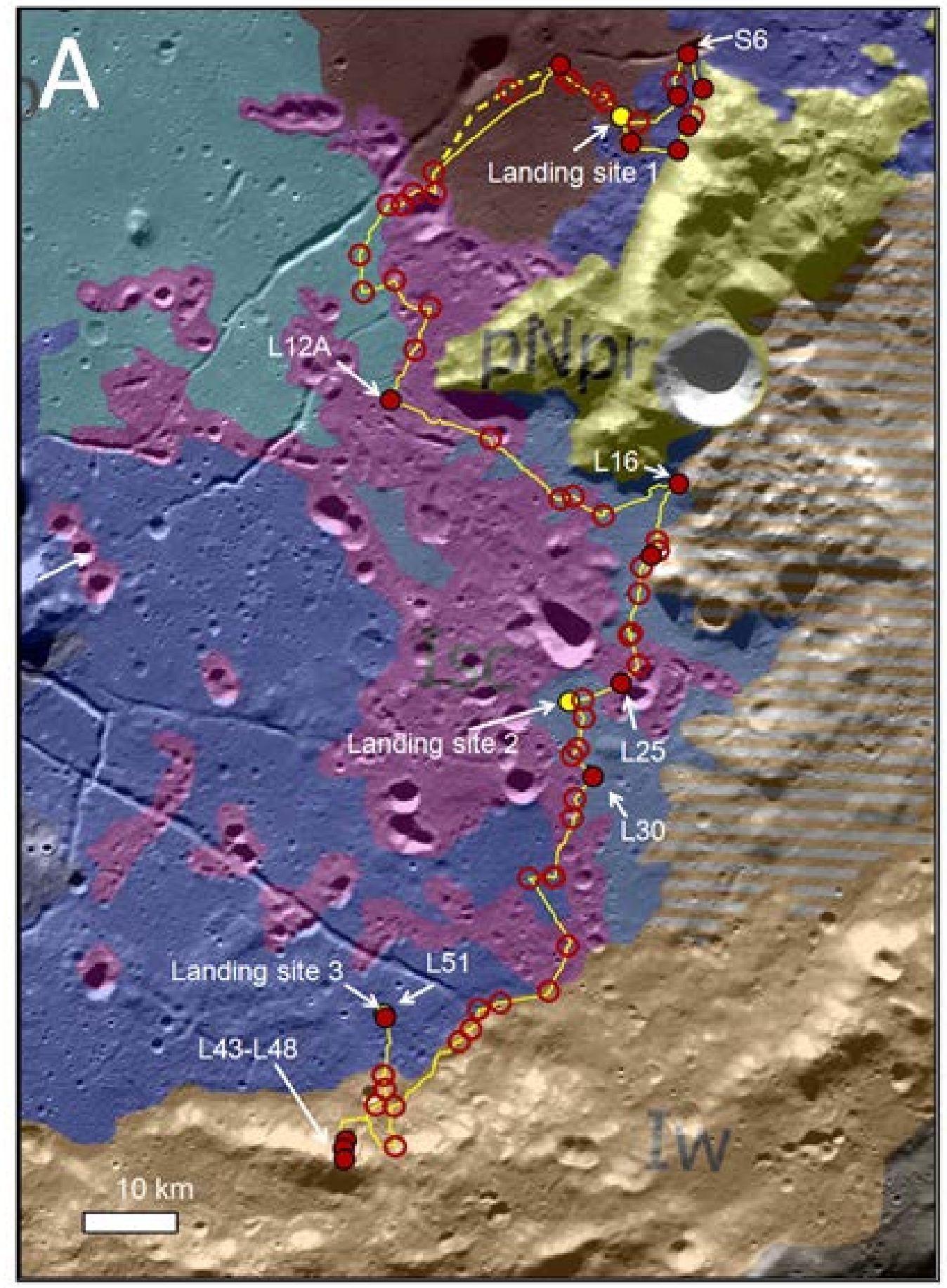



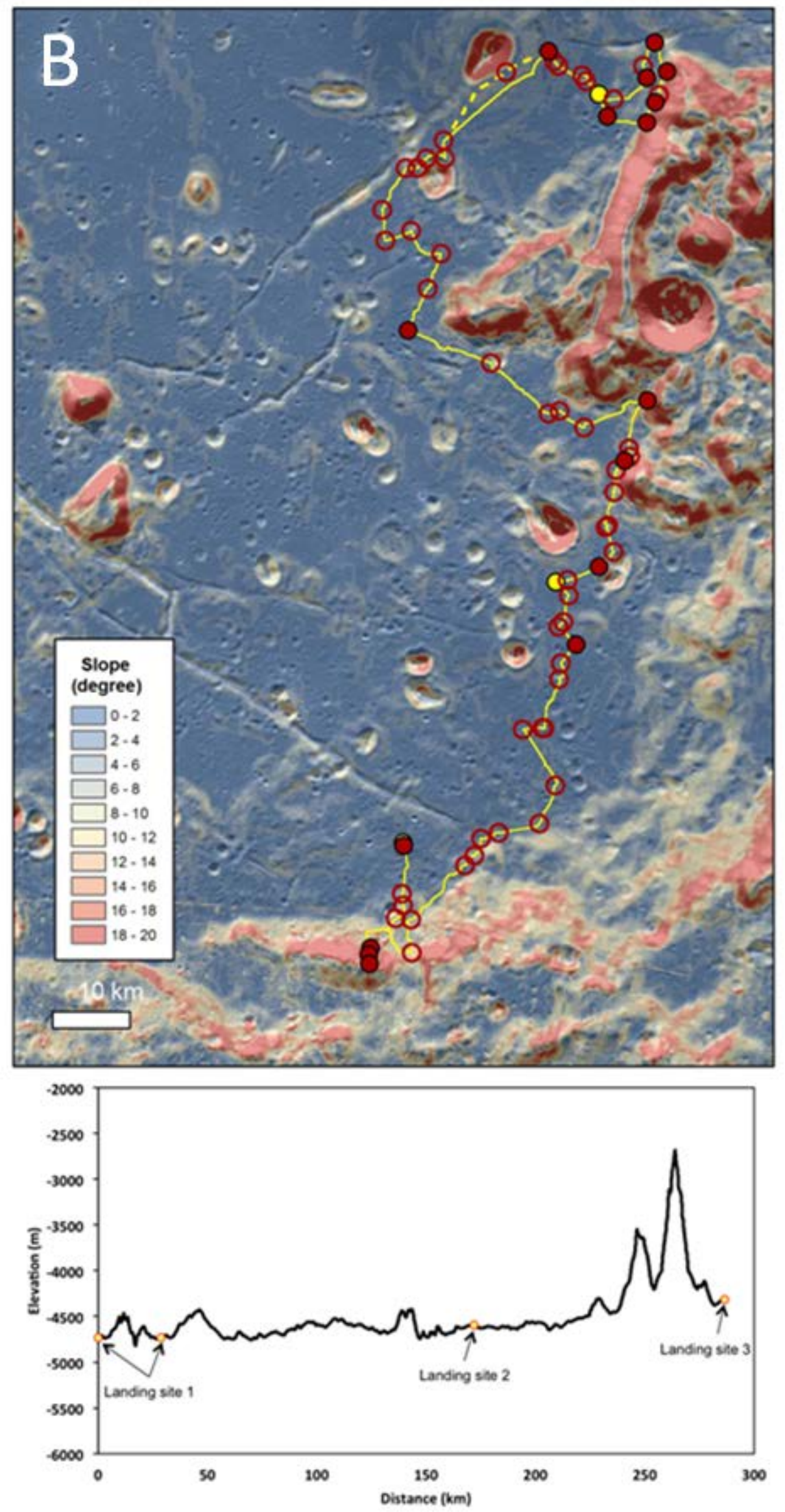
Figure $9 \mathrm{~A}-\mathrm{G}$
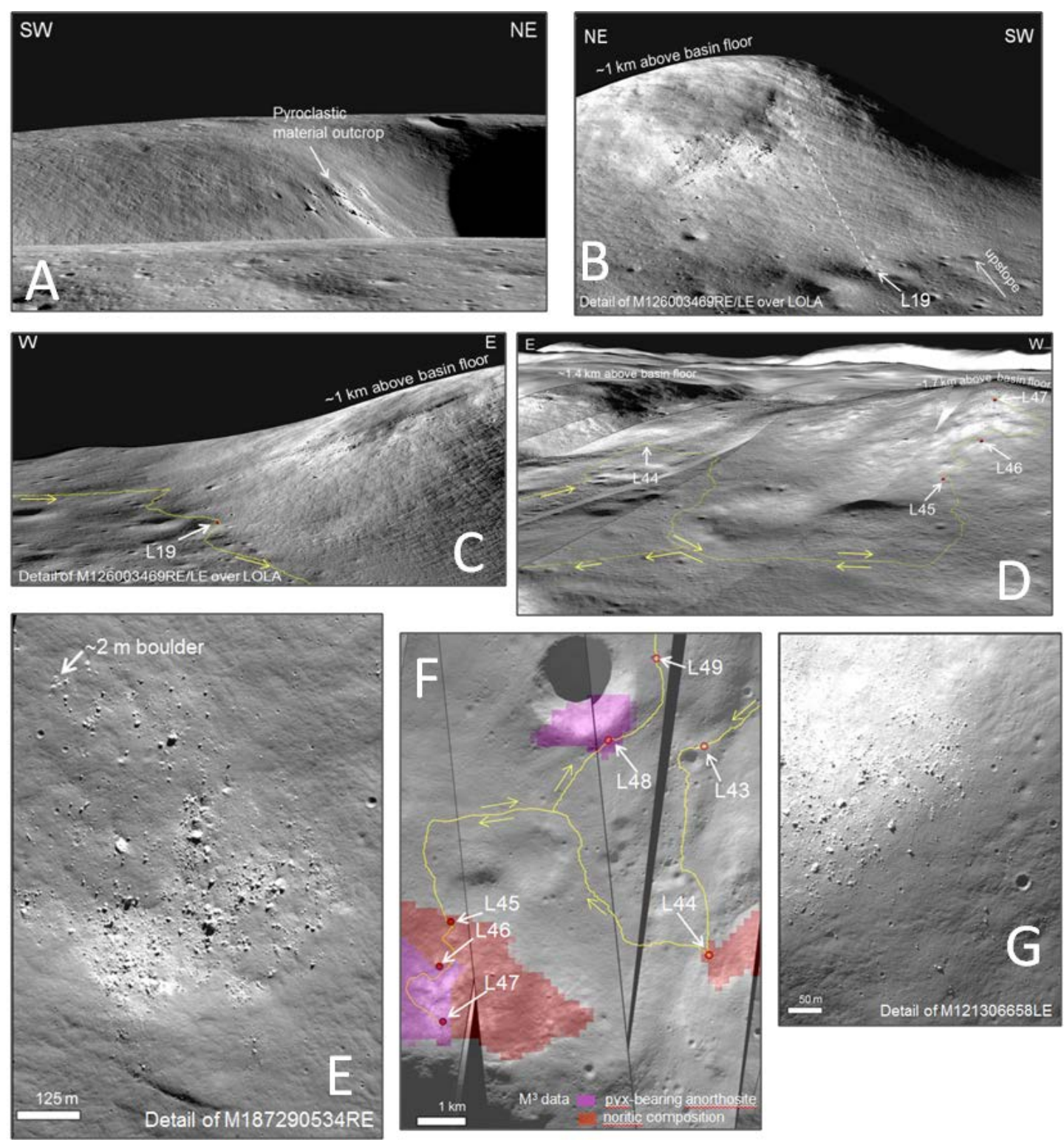
Table 1 Notional instrumentation suite assumed for ConOps assessment.

\begin{tabular}{|c|c|c|c|c|}
\hline Instrument & Dimensions (cm) & Weight (kg) ${ }^{a}$ & Power (W) ${ }^{\mathrm{a}}$ & Data rate (kbps) \\
\hline 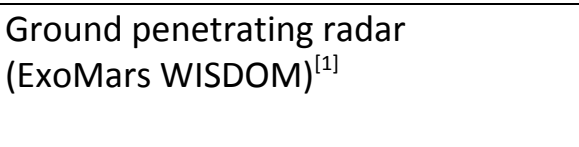 & $\begin{array}{c}\text { Sensor: } 10 \times 10 \times 1 \\
\text { Electronics: } \\
10 \times 6 \times 6\end{array}$ & $<3.50$ & $<7.8$ & 44.5 \\
\hline $\begin{array}{l}\text { Arm-mounted Alpha } \\
\text { Particle X-Ray spectrometer (MER) }{ }^{[2]}\end{array}$ & $10.5 \times 6 \times 9$ & $<2.20$ & $<7.3$ & $18.0^{* *}$ \\
\hline Gamma Ray spectrometer (JH APL) ${ }^{[3]}$ & $\begin{array}{l}\text { Sensor: } 8 \times 8 \times 8 \\
\text { DPU: } 10 \times 15 \times 5\end{array}$ & $<1.82$ & $<3.25$ & $0.01-0.1$ \\
\hline 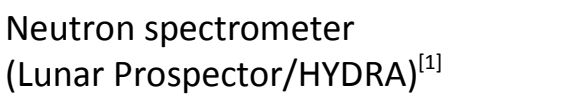 & $18 \times 12 \times 6$ & $<0.65$ & $<1.8$ & 0.5 \\
\hline Microscope camera (MER) ${ }^{[2]}$ & $8 \times 8 \times 10$ & $<0.4$ & $<0.4$ & $8000^{b}$ \\
\hline 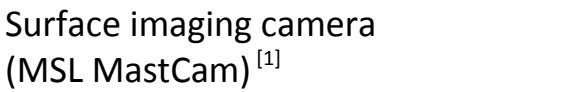 & $11 \times 29 \times 12$ & $<1.0$ & $<11.0$ & 1.26 \\
\hline
\end{tabular}

Table 2 ConOps used for traverse times assuming the notional instrumental payload from Table 1.

\begin{tabular}{|c|c|}
\hline Station Activities & Time (Earth hours) $^{\text {a }}$ \\
\hline $\begin{array}{l}\text { Panoramic image using 3D imager (HD video } \\
\text { feed at other times) }{ }^{[1]}\end{array}$ & 8 \\
\hline Position rover for in-situ target ${ }^{[1]}$ & 0.5 \\
\hline GPR analysis ${ }^{[2]}$ & On while traversing \\
\hline Neutron sensor analysis ${ }^{[2]}$ & On as when needed including during traversing \\
\hline Position arm-mounted APXS ${ }^{[1]}$ & 0.5 \\
\hline APXS analysis ${ }^{[4]}$ & 3.0 \\
\hline Position GRS ${ }^{[1]}$ & 0.5 \\
\hline GRS analysis $^{[3]}$ & 1.0 \\
\hline Position microscope camera $\left(\right.$ LRAC) ${ }^{[1]}$ & 0.5 \\
\hline Microscope camera (LRAC) ${ }^{[4]}$ & 1.0 \\
\hline Surface imager (MSL MastCam) ${ }^{[2]}$ & 0.5 \\
\hline Sample collection ${ }^{[1] \mathrm{b}}$ & 3.0 \\
\hline Sample transfer to bag and storage ${ }^{[1]}$ & 1.0 \\
\hline $\begin{array}{l}\text { Assuming one analysis per type of in-situ analysis } \\
{ }^{2} \text { Sample collection may vary considerably dependent o }\end{array}$ & tion method \\
\hline
\end{tabular}


Table 3 Summary of the NRC (2007) science goals that can be addressed within the short (a) and long traverse (b). Goals that with reasonable certainty can be addressed within the traverse are indicated in dark grey, goals that may be addressed are indicated in light grey and the top 10 of the highest science priorities are in italic and bold.

\begin{tabular}{|c|c|c|c|c|c|}
\hline & a & b & c & D & e \\
\hline $\begin{array}{l}\text { 1: Bombardment history of } \\
\text { the inner solar system }\end{array}$ & Test cataclysm hypothesis & $\begin{array}{l}\text { Early Earth-Moon impact flux } \\
\text { and age of SPA basin }\end{array}$ & $\begin{array}{l}\text { Establish absolute } \\
\text { chronology }\end{array}$ & Recent impact flux & $\begin{array}{l}\text { Role of secondary craters } \\
\text { on crater counts }\end{array}$ \\
\hline $\begin{array}{l}\text { 2: Structure and composition } \\
\text { of the lunar interior }\end{array}$ & $\begin{array}{l}\text { Thickness and lateral } \\
\text { variability of lunar crust }\end{array}$ & $\begin{array}{c}\text { Chemical and physical } \\
\text { stratification of lunar mantle }\end{array}$ & $\begin{array}{c}\text { Size, composition and } \\
\text { physical state of lunar core }\end{array}$ & $\begin{array}{l}\text { Thermal state and } \\
\text { evolution of lunar interior }\end{array}$ & \\
\hline $\begin{array}{l}\text { 3: Diversity of lunar } \\
\text { crustal rocks }\end{array}$ & $\begin{array}{l}\text { Extent and composition of } \\
\text { differentiation products }\end{array}$ & $\begin{array}{l}\text { Age, distribution and origin of } \\
\text { lunar rock types }\end{array}$ & $\begin{array}{c}\text { Composition of lower crust } \\
\text { and bulk Moon }\end{array}$ & $\begin{array}{l}\text { Local and regional } \\
\text { complexity of lunar crust }\end{array}$ & $\begin{array}{c}\text { Extent and structure of } \\
\text { megaregolith }\end{array}$ \\
\hline $\begin{array}{l}\text { 4: Lunar poles and } \\
\text { volatiles }\end{array}$ & $\begin{array}{l}\text { Compositional state and } \\
\text { distribution of volatiles }\end{array}$ & $\begin{array}{c}\text { Source(s) for lunar polar } \\
\text { volatiles }\end{array}$ & $\begin{array}{c}\text { Dynamical processes of } \\
\text { polar volatiles }\end{array}$ & $\begin{array}{l}\text { Physical properties of cold } \\
\text { polar regolith }\end{array}$ & $\begin{array}{c}\text { Polar regolith and ancient } \\
\text { solar environment }\end{array}$ \\
\hline 5: Lunar volcanism & $\begin{array}{l}\text { Origin and variability of } \\
\text { basalts }\end{array}$ & $\begin{array}{c}\text { Age of youngest and oldest } \\
\text { mare basalts }\end{array}$ & $\begin{array}{l}\text { Compositional range and } \\
\text { extent of pyroclastics }\end{array}$ & $\begin{array}{c}\text { Flux and evolution of lunar } \\
\text { volcanism }\end{array}$ & \\
\hline 6: Impact processes & $\begin{array}{l}\text { Existence and extent of } \\
\text { melt sheet differentiation }\end{array}$ & $\begin{array}{c}\text { Structure of multi-ring impact } \\
\text { basins }\end{array}$ & $\begin{array}{c}\text { Physical aspects of crater } \\
\text { formation }\end{array}$ & $\begin{array}{l}\text { Lateral and vertical mixing } \\
\text { of ejecta and local material }\end{array}$ & \\
\hline 7: Regolith processes & $\begin{array}{l}\text { Characterizing ancient } \\
\text { regolith }\end{array}$ & Physical properties of regolith & $\begin{array}{l}\text { Regolith modification } \\
\text { processes }\end{array}$ & $\begin{array}{l}\text { Studying rare materials in } \\
\text { regolith }\end{array}$ & \\
\hline
\end{tabular}




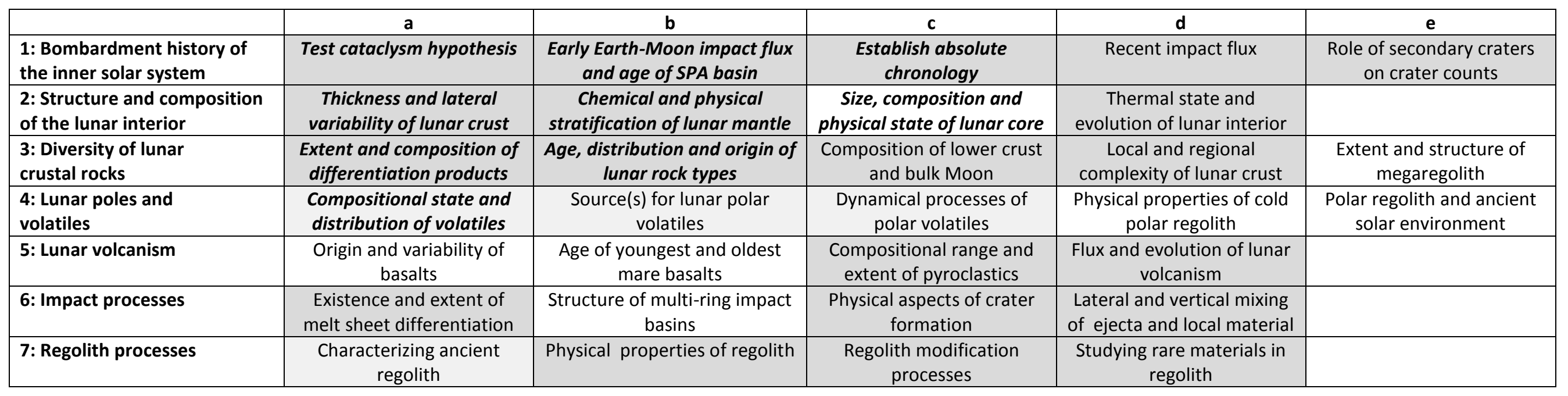


